\title{
CpG oligodeoxynucleotide nanomedicines for the prophylaxis or treatment of cancers, infectious diseases, and allergies
}

This article was published in the following Dove Press journal:

International Journal of Nanomedicine

16 January 2017

Number of times this article has been viewed

\author{
Nobutaka Hanagata ${ }^{1,2}$ \\ 'Nanotechnology Innovation Station, \\ National Institute for Materials \\ Science, Tsukuba, Ibaraki, ${ }^{2}$ Graduate \\ School of Life Science, Hokkaido \\ University, Sapporo, Hokkaido, Japan
}

Correspondence: Nobutaka Hanagata Nanotechnology Innovation Station, National Institute for Materials Science, I-2-I Sengen, Tsukuba, Ibaraki 305-0047, Japan

Tel +81298604774

Fax +8I 298592475

Email hanagata.nobutaka@nims.go.jp

\begin{abstract}
Unmethylated cytosine-guanine dinucleotide-containing oligodeoxynucleotides (CpG ODNs), which are synthetic agonists of Toll-like receptor 9 (TLR9), activate humoral and cellular immunity and are being developed as vaccine adjuvants to prevent or treat cancers, infectious diseases, and allergies. Free CpG ODNs have been used in many clinical trials implemented to verify their effects. However, recent research has reported that self-assembled CpG ODNs, protein/peptide-CpG ODN conjugates, and nanomaterial-CpG ODN complexes demonstrate higher adjuvant effects than free CpG ODNs, owing to their improved uptake efficiency into cells expressing TLR9. Moreover, protein/peptide-CpG ODN conjugates and nanomaterial-CpG ODN complexes are able to deliver CpG ODNs and antigens (or allergens) to the same types of cells, which enables a higher degree of prophylaxis or therapeutic effect. In this review, the author describes recent trends in the research and development of CpG ODN nanomedicines containing self-assembled CpG ODNs, protein/peptide-CpG ODN conjugates, and nanomaterial-CpG ODN complexes, focusing mainly on the results of preclinical and clinical studies.
\end{abstract}

Keywords: CpG oligodeoxynucleotides, Toll-like receptor 9, immunostimulation, nanomedicine, adjuvant

\section{Introduction}

Oligodeoxynucleotides (ODNs) containing unmethylated cytosine-guanine dinucleotides $(\mathrm{CpG})$ stimulate cells that express Toll-like receptor 9 (TLR9) and activate humoral or cellular immunity by inducing inflammatory cytokines and type I interferon (IFN). In humans, TLR9 is expressed only in plasmacytoid dendritic cells (pDCs) and B cells. ${ }^{1-4}$ However, in mice, in addition to the aforementioned cell types, TLR9 is also expressed in macrophages and myeloid dendritic cells (mDCs). ${ }^{5-7}$ More than 600 preclinical studies investigating the treatment or prevention of cancers, infections, and allergies with CpG ODNs have been implemented to date ${ }^{8}$ and more than 100 clinical trials have either been completed or are currently in progress. ${ }^{9}$ Many of the CpG ODNs developed to date have been single-stranded synthetic ODNs with 20 bases, and they are divided broadly into four classes depending upon the differences in their structure and immunoreactivity. Of these four classes, almost all the $\mathrm{CpG}$ ODNs used in clinical trials have been class-B CpG (CpG-B) ODNs (also known as K-type ODNs), whereas class-A CpG (CpG-A) ODNs (also known as D-type ODNs) have also been used but in fewer clinical trials. All the nucleotides of CpG-B ODNs are phosphorothioated and contain one or more nonpalindromic CpGs in the base sequence. ${ }^{10-13}$ Phosphorothioated DNA is more resistant to DNase than natural phosphodiester DNA, ${ }^{14,15}$ which makes it possible to extend the length of time that the 
nucleotide resides in the body. ${ }^{16} \mathrm{CpG}-\mathrm{B}$ ODNs are recognized by TLR9 localized in endosomes of B cells, pDCs, mDCs, and macrophages, inducing inflammatory cytokines $;^{10-13}$ however, no type I IFN is induced. ${ }^{6} \mathrm{CpG}-\mathrm{A}$ ODNs have a phosphorothioate backbone poly-G tail at both ends of the phosphodiester backbone palindromic $\mathrm{CpG}$ sequence, ${ }^{10,11,17}$ and they form complex higher order structures through selfassociation under physiological conditions. ${ }^{18,19}$ This class of CpG ODNs is recognized by TLR9 in pDCs, mDCs, and macrophages, inducing type I IFNs like IFN- $\alpha / \beta$ from these cells, but they have no effect on B cells. ${ }^{10,11,17}$

The problem in the clinical application of DNA pharmaceuticals like CpG ODNs is the degradation of these drugs by DNase. Therefore, the nucleotides of CpG-A ODNs are partially phosphorothioated, and all the nucleotides of $\mathrm{CpG}-\mathrm{B}$ ODNs are phosphorothioated. The half-life of phosphorothioated DNA in vivo is 30-60 minutes, which is a longer lifespan than the half-life of nonphosphorothioated natural phosphodiester DNA (5-10 minutes), ${ }^{16}$ but this is still not an adequate length of time. Moreover, DNA with a negative charge is repelled by cell surfaces that are negatively charged, which makes it difficult to attain a highly efficient uptake rate into cells. To resolve these issues, research is under way on $\mathrm{CpG}$ ODN nanomedicines such as self-assembled $\mathrm{CpG}$ ODNs, protein/peptide-CpG ODN conjugates, and nanoparticleCpG ODN complexes. With CpG ODN nanomedicines, a high immunostimulatory effect can be expected even with natural phosphodiester CpG ODNs, which means it is possible to avoid the various associated adverse drug reactions ${ }^{20-28}$ that were a concern with phosphorothioated CpG ODNs. Furthermore, the immunoreactivity of $\mathrm{CpG}$ ODN changes depending upon its formation of complexes with proteins (or peptides) or nanoparticles, ${ }^{29-31}$ and ODNs without $\mathrm{CpG}$ can be made recognizable to TLR9. ${ }^{32,33}$ These findings enable a broad range of research strategies for $\mathrm{CpG}$ ODN nanomedicines.

In this review, the action mechanism of CpG ODNs as a vaccine adjuvant in the prevention and treatment of cancers, infections, and allergies is first explained, and then the development trends of $\mathrm{CpG}$ ODN nanomedicines in recent years are introduced. Furthermore, the problem areas in the development of $\mathrm{CpG}$ ODN nanomedicines and their future prospects will be discussed.

\section{Action of CpG ODNs as an adjuvant Action of CpG ODNs in cancer immunotherapy}

Cancer immunotherapy is a therapeutic method in which cytotoxic $\mathrm{T}$ lymphocytes (CTLs) recognize protein-derived peptides (tumor-associated antigens [TAAs]) that are expressed specifically on tumor cells, thereby differentiating between normal and tumor cells and killing only the TAA-expressing tumor cells. Therefore, cancer immunotherapy could be referred to as a therapy that mainly utilizes cellular immunity. Naïve $\mathrm{CD}^{+} \mathrm{T}$ cells recognize the TAAs presented by class I major histocompatibility complexes (MHC-I) and mature into CTLs. However, it is difficult for naïve $\mathrm{CD}^{+} \mathrm{T}$ cells to mature into TAA-specific CTLs with killing activity even if naïve $\mathrm{CD}^{+} \mathrm{T}$ cells interact with the TAA-MHC-I complex on cancer cells, because cancer cells do not express costimulatory molecules such as CD80 and CD86. ${ }^{34}$ In contrast, pDCs express the costimulatory molecules CD80 and CD86 together with MHC-I. When TAAs are taken up by pDCs, the TAA is presented on $\mathrm{MHC}-\mathrm{I}$, and naïve $\mathrm{CD}^{+} \mathrm{T}$ cells that recognize these cells mature into TAA-specific CTLs. Therefore, it is possible to induce the maturation of naïve $\mathrm{CD} 8^{+} \mathrm{T}$ cells into TAA-specific CTLs by presenting the TAA to pDCs.

pDCs also express MHC-II in addition to MHC-I. Naïve $\mathrm{CD}^{+} \mathrm{T}$ (Th0) cells that recognize the TAA on MHC-II differentiate into a variety of effector $\mathrm{CD} 4^{+} \mathrm{T}$ cells, including TAA-specific helper $1 \mathrm{~T}$ (Th1) cells or TAA-specific helper 2 $\mathrm{T}$ (Th2) cells. These effector $\mathrm{CD}^{+} \mathrm{T}$ cells activate the differentiation of B cells into plasma cells, resulting in the induction of TAA-specific antibodies. These antibodies induce growth inhibition and/or apoptosis in cancer cells by several mechanisms such as antibody-dependent cell-mediated cytotoxicity and complement-dependent cytotoxicity. ${ }^{35}$

Th1 cells enhance the cytotoxic activity of CTLs, and secrete cytokines such as IFN- $\gamma$ and tumor necrosis factor alpha (TNF- $\alpha$ ), thereby inducing the cytostasis associated with the aging of cancer cells. ${ }^{36,37}$

$\mathrm{CpG}$ ODNs increase the expression of costimulatory molecules such as CD40, CD80, and CD86 in pDC as well as MHC, which results in naïve T cells maturing into CTLs and effector $\mathrm{CD}^{+}{ }^{+}$cells. ${ }^{38-41}$ Furthermore, CpG ODNs induce the secretion of not only higher levels of IFN- $\alpha$ from $\mathrm{pDCs}^{10,11,17}$ but also inflammatory cytokines such as interleukin (IL)-6, IL-12, and TNF- $\alpha{ }^{42}$ IFN- $\alpha$ enhances the CTL memory function, ${ }^{43-45}$ while IL-12 induces the differentiation of Th0 cells into Th1 cells. ${ }^{38,46,47}$ Additionally, IFN- $\alpha$ and TNF- $\alpha$ secreted from pDCs activate both natural killer (NK) cells and natural killer T (NKT) cells. ${ }^{48}$

The CpG ODN recognized by TLR9 in pDCs enhances the host response to TAA, whereas myeloid-derived suppressor cells (MDSCs) residing in tumor tissues create an immunosuppressive milieu, which interferes with the action of $\mathrm{CpG}$ ODN. However, it has been reported that the 
immunosuppressive activity of MDSCs can be reduced by the direct injection of CpG ODN into tumor tissues. ${ }^{49}$

\section{Action of CpG ODNs in infection prevention and treatment}

Vaccines (antigens) mainly induce humoral immunity to prevent infection. Therefore, vaccines induce the production of antibodies, and the pathogens are prevented from infecting the host cells through the action of antibody neutralization or opsonization.

CpG ODNs activate B-cell differentiation into plasma cells, which have the effect of enhancing antibody production. Generally, naïve B cells never express TLR9, so they do not respond to CpG ODNs. ${ }^{12,50}$ Accordingly, it is essential to stimulate naïve $B$ cells in advance with antigens, to ensure that the cells differentiate into plasma cells following CpG ODN activation. ${ }^{51}$ These antigen-stimulated naïve $\mathrm{B}$ cells mature into antigen-specific B cells, which express TLR9. ${ }^{50,52}$ When antigen-specific B cells are stimulated by CpG ODNs, the expression of costimulatory molecules such as MHC-II, CD40, CD80, and CD86, as well as Fc receptors is increased, ${ }^{53-55}$ and the $\mathrm{B}$ cells differentiate into antigensecreting plasma cells. ${ }^{56}$

Furthermore, antigen-specific B cells stimulated by $\mathrm{CpG}$ ODNs secrete IL-6, ${ }^{53,57,58}$ a cytokine that promotes the proliferation and activation of antigen-specific B cells. ${ }^{56,59}$ Additionally, pDCs stimulated by CpG ODNs secrete IL-12, which promotes the differentiation of Th0 cells into Th1 cells. ${ }^{38,46,47}$ Th1 cells promote the differentiation of B cells into plasma cells, and immunoglobulin $\mathrm{M}$ (IgM) switches classes to IgG2. ${ }^{60}$

Conversely, viruses that have infected the host cells cannot be damaged by antibodies, and so the infected host cells undergo apoptosis by CTLs. The action of the CpG ODN in this case is similar to its induction of cellular immunity described in the section "Action of $\mathrm{CpG}$ ODNs in cancer immunotherapy".

\section{Action of CpG ODNs in allergy prevention and treatment}

In allergies induced by house dust mites and ragweed, pDCs that have captured the allergens secrete Th2 cytokines such as IL-4 and IL-5, which develop by inducing the production of allergen-specific IgE from plasma cells. ${ }^{61,62}$ Allergen-specific $\mathrm{IgE}$ binds to $\mathrm{IgE}$ receptors on mast cells, and when the $\mathrm{IgE}$ on the receptor further binds with the allergen, granules are released from the mast cells, causing symptoms like runny nose and sneezing. Continued exposure to the allergen can lead to lung inflammation characterized by lung eosinophilia and airway obstruction. ${ }^{63}$ Allergy immunotherapy is a therapeutic technique that induces Th1 immunity with an allergen vaccine and inhibits Th2 immunity. ${ }^{64-67}$

CpG ODNs stimulate pDCs and B cells, inducing the secretion of IL-12 and the differentiation of Th0 cells into Th1 cells. The IFN- $\gamma$ secreted from Th1 cells reduces the Th2-biased response and inhibits IgE secretion. ${ }^{68-72}$

\section{CpG ODN nanomedicines}

Many studies on $\mathrm{CpG}$ ODN nanomedicines have been conducted for protecting $\mathrm{CpG}$ ODNs from degradation by $\mathrm{DNases}$ and/or improving their uptake efficiency into cells. These $\mathrm{CpG}$ ODN nanomedicines fall into several categories including self-assembled $\mathrm{CpG}$ ODNs, $\mathrm{CpG}$ ODNs conjugated/complexed with proteins or peptides, and $\mathrm{CpG}$ ODNs complexed with nanomaterials. Here, recent findings obtained from preclinical and clinical studies are introduced. Tables $1-3$ present a summary of the results from preclinical

Table I Clinical efficacy of self-assembled CpG ODN nanomedicines

\begin{tabular}{|c|c|c|c|c|}
\hline Agent & Target disease & Phase & Outcome & $\overline{\text { Ref }}$ \\
\hline \multirow[t]{3}{*}{ MGNI703 } & Metastatic solid & Phase I in & Confirmation of antitumor effect & 76 \\
\hline & tumors & clinical trial & Determination of safety dose & \\
\hline & $\begin{array}{l}\text { Metastatic colorectal } \\
\text { carcinoma }\end{array}$ & $\begin{array}{l}\text { Phase II in } \\
\text { clinical trial }\end{array}$ & Significant improvement in progression-free survival & 77 \\
\hline $\begin{array}{l}\text { Single-ligated X-DNA } \\
\text { complex }\end{array}$ & $\begin{array}{l}\text { Colitis-associated } \\
\text { colorectal cancer }\end{array}$ & Preclinical test & Improvement in chemotherapeutic effect & 78 \\
\hline \multirow[t]{2}{*}{$\begin{array}{l}\text { Self-gelling hexapod-like } \\
\text { structured CpG ODN }\end{array}$} & Pollen allergy & Preclinical test & $\begin{array}{l}\text { Increased IL- } 12 \text { levels and Cryj I-specific IgG in nasal lavage } \\
\text { fluid but not in serum }\end{array}$ & 81 \\
\hline & (no description) & Preclinical test & Activation of antigen-specific CTL & 80 \\
\hline K3-SPG & Influenza & Preclinical test & $\begin{array}{l}\text { More than } 100 \text {-fold increase in antigen production compared } \\
\text { with that in mice administered the whole inactivated vaccine } \\
\text { Increase in the level of antigen-specific } \operatorname{lgG} 2 \mathrm{a} \text { and } \mathrm{CTL}\end{array}$ & 83 \\
\hline
\end{tabular}

Abbreviations: ODN, cytosine-guanine dinucleotide-containing oligodeoxynucleotide; IL, interleukin; IgG, immunoglobulin G; CTL, cytotoxic T lymphocyte; SPG, schizophyllan. 
Table 2 Clinical efficacy of CpG ODN nanomedicines conjugated/complexed with proteins or peptides

\begin{tabular}{|c|c|c|c|c|}
\hline Agent & Target disease & Phase & Outcome & Ref \\
\hline $\begin{array}{l}\text { OVA-CpG-B ODN } \\
\text { conjugate }\end{array}$ & Tumor & Preclinical test & $\begin{array}{l}\text { Reduction in size of OVA-expressing tumors by activation of } \\
\text { OVA-specific CTL }\end{array}$ & 85 \\
\hline $\begin{array}{l}\text { Cryj2 peptide- } C_{p} G \mathrm{~B} \\
\text { ODN conjugate }\end{array}$ & Pollen allergy & Preclinical test & $\begin{array}{l}\text { Decreased levels of IL-4, IL-5, and Cryj2-specific IgE } \\
\text { No change in the levels of } \lg G 2 a, \lg G 2 b \text {, and IFN- } \gamma\end{array}$ & 86 \\
\hline $\begin{array}{l}\text { Cryjl-CPG B ODN } \\
\text { conjugate }\end{array}$ & Pollen allergy & Preclinical test & Increased levels of $\lg G 2 a, \lg G 2 b$, and IFN- $\gamma$ & 87 \\
\hline \multirow[t]{2}{*}{$\begin{array}{l}\text { Tat-derived peptide- } \\
\text { CpG-B ODN complex }\end{array}$} & $\begin{array}{l}\text { Foot and mouth } \\
\text { disease (FMD) }\end{array}$ & Preclinical test & Induction of FMD virus-specific lgG2a & 90 \\
\hline & Tumor & Preclinical test & $\begin{array}{l}\text { Reduction in size of OVA-expressing tumors by activation of } \\
\text { OVA-specific Thl-mediated responses and OVA-specific CTL }\end{array}$ & 90 \\
\hline
\end{tabular}

Abbreviations: CPG ODN, cytosine-guanine dinucleotide-containing oligodeoxynucleotide; OVA, ovalbumin; CpG-B, class-B CpG; CTL, cytotoxic T lymphocyte; IL, interleukin; Ig, immunoglobulin; IFN- $\gamma$, interferon gamma; ThI, helper I T cells.

and clinical studies concerning $\mathrm{CpG}$ ODN nanomedicines in each category.

\section{Self-assembled CpG ODN nanomedicines}

Self-assembled CpG ODN nanomedicines are immunostimulators that form nanosized $\mathrm{CpG}$ ODN complexes using the complementation between DNA bases. Self-assembled CpG ODNs have improved resistance to DNases compared with free double-stranded CpG ODNs, as well as improved uptake rate into cells, ${ }^{73}$ so it is possible to use natural phosphodiester CpG ODNs rather than phosphorothioated CpG ODNs. Phosphorothioated DNA induces prolongation of the blood clotting time, ${ }^{20-22}$ disruption of cell signaling, ${ }^{23}$ and complement activation, ${ }^{24,25}$ and has been reported to cause thrombocytopenia, anemia, and neutropenia in rats ${ }^{26}$ as well as induce arthritis in mice. ${ }^{27}$ Thus, it is possible to avoid these adverse effects by using self-assembled $\mathrm{CpG}$ ODN nanomedicines, which are formed from natural phosphodiester CpG ODNs only.

When two molecules of the $5^{\prime}$ phosphorylated singlestranded hairpin ODN undergo ligation with T4-DNA ligase, it is possible to form a dumbbell-like structure with single-stranded loops and a double-stranded stem (Figure 1A). ${ }^{74,75} \mathrm{CpG}$ ODNs with this structure do not have

Table 3 Clinical efficacy of nanomaterial-based CpG ODN nanomedicines

\begin{tabular}{|c|c|c|c|c|}
\hline Agent & Target disease & Phase & Outcome & Ref \\
\hline $\begin{array}{l}\text { CPG-B ODN encapsulated in PLGA } \\
\text { particles }\end{array}$ & $\begin{array}{l}\text { House dust } \\
\text { allergy }\end{array}$ & Preclinical test & $\begin{array}{l}\text { Induction of Der p2-specific lgG2a in PLGA } \\
\text { particles I } \mu \mathrm{m} \text { and } 300 \mathrm{~nm} \text { in size } \\
\text { Activation of antigen-specific CTL in PLGA } \\
\text { particles of } 300 \mathrm{~nm} \text { in size }\end{array}$ & 91,92 \\
\hline $\begin{array}{l}\text { CpG-B ODN encapsulated in } \\
\text { PLGA particles with an average size } \\
\text { of } 500 \mathrm{~nm}\end{array}$ & Tumor & Preclinical test & $\begin{array}{l}\text { Reduction in E.G7-OVA tumor size by activation } \\
\text { of OVA-specific ThI responses but not the } \\
\text { activation of OVA-specific CTL }\end{array}$ & 93 \\
\hline $\begin{array}{l}\text { CpG ODN encapsulated in cationic } \\
\text { lipid-assisted PEG-PLA nanoparticles } \\
\text { with an average size of } 120 \mathrm{~nm}\end{array}$ & Hepatitis B & Preclinical test & $\begin{array}{l}\text { Induction of antigen-specific lgG2a } \\
\text { Upregulation of CD69 in CTL }\end{array}$ & 94 \\
\hline \multirow[t]{3}{*}{$\begin{array}{l}\text { CpG-A ODN encapsulated in Q } \beta \text { - } \\
\text { derived virus-like nanoparticles }\end{array}$} & Melanoma & Clinical trial & $\begin{array}{l}\text { Induction of Melan-A-specific CTL in } 14 \text { of } \\
22 \text { patients }\end{array}$ & 95 \\
\hline & $\begin{array}{l}\text { House dust } \\
\text { allergy }\end{array}$ & Clinical trial & $\begin{array}{l}\text { Increase in allergen-specific } \lg G \\
\text { Decrease in allergen-specific } \lg E\end{array}$ & $96-98$ \\
\hline & $\begin{array}{l}\text { House dust } \\
\text { allergy }\end{array}$ & Clinical trial & $\begin{array}{l}\text { No improvement in patients with persistent } \\
\text { moderate-to-severe allergic asthma }\end{array}$ & 99 \\
\hline $\begin{array}{l}\text { CpG ODN encapsulated in } \\
\text { pH-sensitive liposomes }\end{array}$ & $\begin{array}{l}\text { Hepatoma and } \\
\text { colon cancer }\end{array}$ & Preclinical test & $\begin{array}{l}\text { Suppression of tumor growth and improvement } \\
\text { of survival rate by induction of long-term } \\
\text { memory B cells and tumor-specific antigens }\end{array}$ & 100,101 \\
\hline $\begin{array}{l}\text { CpG-B ODN bound to pyridyl } \\
\text { disulfide-functionalized poly(propylene } \\
\text { sulfide) nanoparticles, } 30 \mathrm{~nm} \text { in size }\end{array}$ & $\begin{array}{l}\text { House dust } \\
\text { allergy }\end{array}$ & Preclinical test & $\begin{array}{l}\text { Decreased IL-4, IL-5, and IgE levels in the lung } \\
\text { Decreased number of eosinophils in the lung }\end{array}$ & 111 \\
\hline $\begin{array}{l}\text { CPG-B ODN bound to single-walled } \\
\text { carbon nanotubes }\end{array}$ & Glioma & Preclinical test & $\begin{array}{l}\text { Suppression of tumor growth and improvement } \\
\text { of survival rate by activation of CTL and NK cells }\end{array}$ & 113 \\
\hline
\end{tabular}

Abbreviations: $C_{p}$ G ODN, cytosine-guanine dinucleotide-containing oligodeoxynucleotide; PLGA, poly(lactic-co-glycolic acid); Ig, immunoglobulin; CpG-B, class-B CpG; OVA, ovalbumin; CTL, cytotoxic T lymphocyte; PEG, polyethylene glycol; PLA, polylactic acid; CpG-A, class-A CpG; IL, interleukin; NK, natural killer. 
open ends, so they become resistant to exonucleases. One such synthetic self-assembled TLR9 immunomodulator, MGN1703, which consists of two loops of 30 nucleotides (nt), including three $\mathrm{CpG}$ motifs and a 28 base pair (bp) stem that links these loops, induced IFN- $\alpha$, IL-6, IFN- $\gamma$, IL-12 p40, IL-2, and TNF- $\alpha$ from human peripheral blood mononuclear cells (PBMCs).$^{75}$ Induction of these cytokines suggests that MGN1703 has the potential to activate both cellular immunity and humoral immunity. Furthermore, MGN1703 upregulated the expression of human leukocyte antigen D related and intercellular adhesion molecule-1 in B-lineage RPMI-8226 cells. The immunostimulatory potential of MGN1703 is dependent on the $\mathrm{CpG}$ motif position, loop size, and stem length in the dumbbell-like structure. CpG motifs demonstrate a higher immunostimulatory effect when present in single-stranded loops than in double-stranded stems. Furthermore, the optimal loop size and stem length were $30 \mathrm{nt}$ and $28 \mathrm{bp}$, respectively. In the MGN1703 Phase I clinical trial targeting patients with metastatic solid tumors, the antitumor efficacy and safety of the self-assembled CpG nanomedicine was confirmed, and the dosage was also determined (60 mg twice a week). ${ }^{76}$ The Phase II clinical trial assessed MGN1703 maintenance treatment for metastatic colorectal carcinoma, and the results showed significantly improved progression-free survival. ${ }^{77}$ MGN1703 also increased the IgG2 levels induced by Th1-biased responses in PBMCs. Conversely, it decreased the IgG1 and IgE levels induced by Th2-biased responses. ${ }^{74}$ This suggests that MGN1703 may have not only an antitumor effect but also the capability of preventing or treating allergies.

An X-shaped DNA, composed of four molecules of natural phosphodiester single-stranded CpG ODNs (39 nt each) with an ACGT sticky sequence inserted into the $5^{\prime}$ end, forms a self-ligated X-DNA complex through complementarity with the ACGT sequence (Figure 1B). ${ }^{78}$ This self-ligated X-DNA complex elevated the expression of CD80 and CD86 on mouse bone marrow-derived primary dendritic cells (BMDCs), and induced the secretion

\section{A}

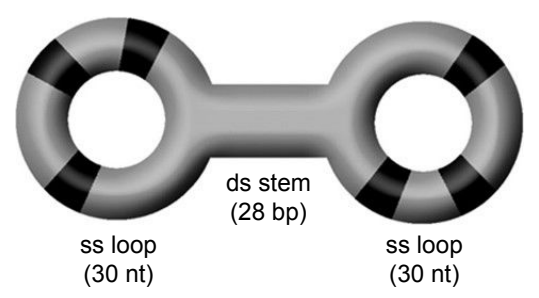

B

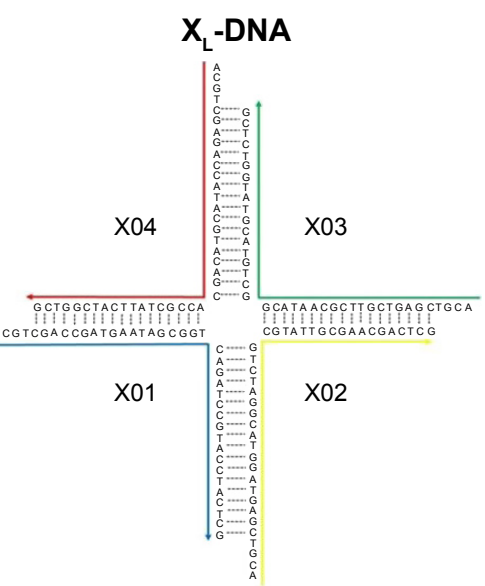

D

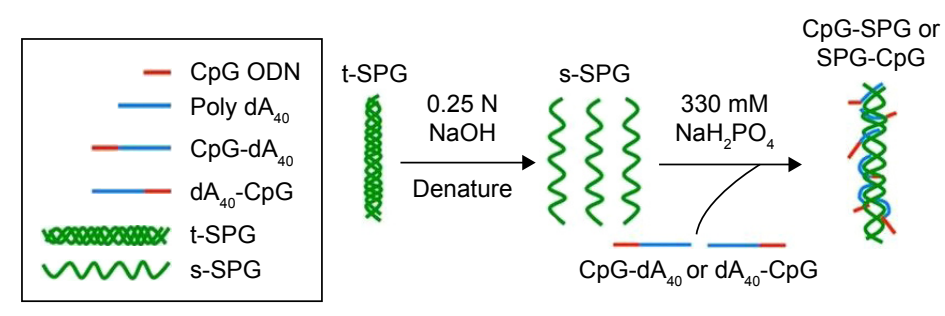

C

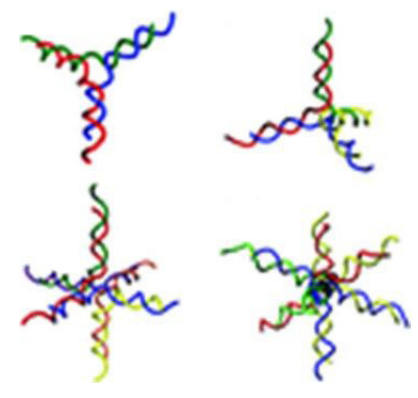

Figure I Self-assembled CPG ODN nanomedicines.

Notes: (A) Double stem loop immunomodulator MGNI 703 with cytosine-guanine (CG) motifs in black. Unmodified from NUCLEIC ACID THERAPEUTICS Vol. 25, Issue 3, 2015, nat.20I5.0533, published by Mary Ann Liebert, Inc., New Rochelle, NY.75 The publisher for this copyrighted material is Mary Ann Liebert, Inc. publishers. (B) X-shaped double-stranded DNA (X-DNA). $\mathrm{X}_{\mathrm{L}}$-DNA forms a ligated complex due to an ACGT sequence at the end of the strand. Adapted from Koo J-E, Shin S-W, Um S-H, Lee J-Y. $X$-shaped DNA potentiates therapeutic efficacy in colitis-associated colon cancer through dual activation of TLR9 and inflammasomes. Mol Cancer. 20I5; I4: I04. ${ }^{78}$ (C) Putative structures of polypodna consisting of three, four, six, or eight ODNs. Adapted with permission from Mohri K, Nishikawa M, Takahashi N, et al. Design and development of nanosized DNA assemblies in polypod-like structures as efficient vehicles for immunostimulatory CpG motifs to immune cells. ACS Nano. 20I2;6(7):593I-5940. Copyright ( ) 2012 American Chemical Society. ${ }^{79}$ (D) CpG ODN complexed with SPG. Adapted with permission from Kobiyama K, Aoshi T, Narita H, et al. Nonagonistic Dectin-I ligand transforms CPG into a multitask nanoparticulate TLR9 agonist. Proc Natl Acad Soc U S A. 20 I 4; I I (8):3086-309I. Copyright @ 20I4 National Academy of Sciences. ${ }^{83}$

Abbreviations: CPG ODN, cytosine-guanine dinucleotide-containing oligodeoxynucleotide; ds, double strand; ss, single strand; nt, nucleotides; bp, base pairs; t-SPG, triplestranded schizophyllan; s-SPG, single-stranded SPG. 
of IL-12p40 and TNF- $\alpha$. The levels of costimulatory molecules and cytokines induced from BMDCs by the self-ligated X-DNA complex were significantly higher than those induced by a nonself-ligated single X-DNA unit. This is thought to be due to improved uptake of the X-DNA complex through endocytosis, attributed to the size enlargement caused by self-ligation. In mouse models where colitis-associated colorectal cancer was induced with dextran sodium sulfate treatment in combination with azoxymethane, the number of colonic polyps larger than $3 \mathrm{~mm}$ was significantly reduced when doxorubicin $(1 \mathrm{mg} / \mathrm{kg})$ and the self-ligated X-DNA complex ( 2.5 or $5 \mathrm{mg} / \mathrm{kg}$ ) were administered simultaneously, compared with doxorubicin monotherapy; this suggests that the dose of anticancer drugs can be reduced with the coadministration of such complexes. Although the self-ligated X-DNA complex activates Th1 immunity and self-assembled CpG ODN nanomedicines activate the inflammasome complex, it is thought that IL-1 $\beta$ also contributes to the antitumor effect. Moreover, the selfligated X-DNA complex increases the expression of IFN- $\beta$ genes in BMDCs, so we may not be able to ignore the effect of this cytokine.

Research relating to the self-ligated X-DNA complexes suggests that the properties of the branched ODN assembly can influence the $\mathrm{CpG}$ ODN performance. Mohri et al ${ }^{79}$ synthesized polypod-like structures through self-assembly of 3-8 ODN molecules each of which contains $\mathrm{CpG}$ motifs (Figure 1C), and investigated the relationship between the branched CpG ODN assembly properties and the immunostimulation effects. All the polypod-like CpG ODNs that were synthesized through self-assembly of natural phosphodiester ODNs of 30-90 nt were $\sim 10 \mathrm{~nm}$. When mouse macrophage-like RAW264.7 cells were stimulated with these self-assembled polypod-like CpG ODNs, the secretion of proinflammatory cytokines, such as TNF- $\alpha$ and IL-6, was induced. Generally, the level of cytokines secreted was greater in cells stimulated with a higher pod number (ie, the number of ODNs in the polypod-like structure). A higher pod number increased the uptake of the polypod-like structure by the cells. Conversely, however, the resistance to DNase decreased. Thus, the increased secretion level of proinflammatory cytokines due to the increased pod number is thought to be the cause of increased efficiency in cellular uptake. Furthermore, it has also been reported that increasing the concentration of these polypod-like CpG ODNs, increasing the salt concentration in the solvent, or forcing the polypodlike CpG ODNs to self-associate with other DNA results in the formation of a hydrogel by the CpG ODNs. ${ }^{80}$ In the self-association process where the polypod-like CpG ODNs are forced to undergo self-association with other DNA, it is possible to incorporate antigens into the self-gelling DNA. Ishii-Mizuno et al ${ }^{81}$ prepared a CpG ODN hydrogel, containing the Japanese cedar pollen allergen Cryj1, through self-gelling of two types of hexapod-like CpG ODNs with a $5^{\prime}$-end complementary sequence. The Cryj1-containing CpG ODN hydrogel was administered intranasally to mice and the retention time was 3-4 hours, which was longer than the retention time ( 0.5 hours) from when a mixture of Cryj 1 and hexapod-like CpG ODNs that did not form a hydrogel was administered. Additionally, with intranasal administration of the Cryj1-containing CpG ODN hydrogel, the level of IL-12 and Cryj1-specific IgG in the nasal lavage fluid increased, but the level of IL-12 and Cryj1-specific IgG in the serum did not increase. Furthermore, when spleen cells were isolated from mice that had received intranasal administration of this Cryj1-containing CpG ODN hydrogel and Cryj1 was restimulated in vitro, the secretion volume of IL-12 and IFN- $\gamma$ increased markedly, which suggests activation of Th1-biased responses. These results demonstrate that a $\mathrm{CpG}$ ODN hydrogel loaded with an allergen is effective in treating or preventing pollen allergies. Moreover, in mice injected with a CpG ODN hydrogel loaded with the model antigen ovalbumin (OVA), the OVA-specific CTL was activated. ${ }^{80}$ Thus, the CpG ODN hydrogel could be applied to the treatment of infectious diseases and to cancer immunotherapy.

Another fascinating self-assembled CpG ODN nanomedicine is the hybrid nanoparticles formed through self-assembly of polysaccharides and single-stranded $\mathrm{CpG}$ ODNs. The soluble $\beta$-glucan schizophyllan (SPG) forms a triple helix through self-assembly. This triple helix denatures in $\mathrm{NaOH}$ and forms single-stranded SPG. If polydeoxyadenylic acid (poly-A) is present when the single-stranded SPG is renatured in $\mathrm{NaHPO}_{4}$, it forms a triple-helical complex composed of a two-molecule single-stranded SPG and a one-molecule poly-A (Figure 1D). ${ }^{82}$ The triple-helical complex (K3-SPG) composed of a one-molecule $\mathrm{CpG}$ ODN and a two-molecule single-stranded SPG, linking $40 \mathrm{nt}$ of phosphorothioated poly-A to the $3^{\prime}$ end of $\mathrm{K} 3$, known as CpG-B ODN, formed rod-like nanoparticles with a free rotation diameter of $\sim 30 \mathrm{~nm} .{ }^{83}$ These self-assembled K3-SPG nanoparticles induced the secretion of IFN- $\alpha$ and IFN- $\gamma$ from PBMCs. Additionally, when K3-SPG was administered to mice at the same time as OVA, there was increased production of OVA-specific IgG2c antibodies and induction of OVAspecific CTLs. These results suggest that self-assembled K3-SPG nanoparticles activate both humoral and cellular 
immune responses. Therefore, the effectiveness of K3-SPG as an adjuvant to the influenza vaccine was investigated. In mice administered hemagglutinin antigen-enriched virion-free split vaccine (SV) and K3-SPG, the antibody production increased more than 100 times compared to those administered the whole inactivated vaccine only. Furthermore, with a single administration of SV or whole inactivated vaccine, the survival rate after lethal PR8 virus challenge was $\sim 10 \%$ compared with a $100 \%$ survival rate in mice administered both SV and K3-SPG. The effect of $\mathrm{K} 3-\mathrm{SPG}$ as an adjuvant for the influenza vaccine was also confirmed with cynomolgus monkeys.

\section{CPG ODN nanomedicines conjugated/ complexed with proteins or peptides}

$\mathrm{CpG}$ ODN nanomedicines conjugated with a protein or peptide (protein/peptide) can be broadly divided into two types. One is a conjugate type where $\mathrm{CpG}$ ODN is covalently bonded to a protein/peptide, and the other is a conjugate type where $\mathrm{CpG}$ ODN is bonded to a cationic protein/peptide through electrostatic interaction.
In the first type, covalently bonding $\mathrm{CpG}$ ODN to an antigen or allergen enables uptake of the adjuvant $\mathrm{CpG}$ ODN into the same antigen-presenting cell in which the antigen or allergen has been taken up as a vaccine. The typical procedure for covalently bonding a $\mathrm{CpG}$ ODN to a protein/peptide is to modify the protein/peptide and CpG ODN with a maleimide group and a thiol group, respectively, and utilize the cross-linking of these groups. When the model antigen OVA is reacted with sulfosuccinimidyl-4- $(\mathrm{N}-$ maleimidomethyl)cyclohexane-1-carboxylate (SMCC), the amino side chains of the lysine residues are modified with maleimide groups. Mixing the maleimide-modified OVA with the thiolated $\mathrm{CpG}-\mathrm{B}$ ODN and incubating the mixture will yield OVA-CpG-B ODN conjugates (Figure 2A). BMDCs stimulated with these conjugates showed upregulated expression of MHC-II, CD86, and CD40, and induced the secretion of proinflammatory cytokines such as IL-12p40 and TNF- $\alpha .{ }^{84}$ Furthermore, the OVA-CpG-B ODN conjugate activated OVA-specific CTLs. ${ }^{84,85}$ It has been reported that when the conjugates were administered to mice transplanted with OVA-expressing tumor cells,

A
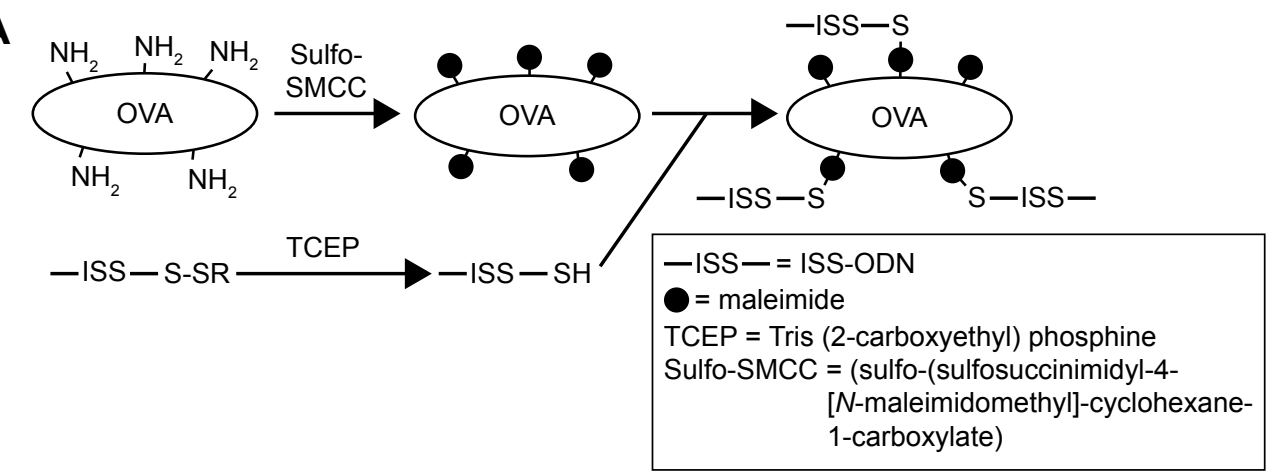

B a


Figure 2 CpG ODN nanomedicines conjugated with protein or peptide.

Notes: (A) Procedure of CPG containing thiolated immunostimulatory DNA sequence (ISS) conjugated with maleimide-modified OVA. Adapted with permission from Macmillan Publishers Ltd: Nature Biotechnology. Cho HJ, Takabayashi K, Cheng P-M, et al. Immunostimulatory DNA-based vaccines induce cytotoxic lymphocyte activation by a T-helper cell-independent mechanism, 2000; 18(5):509-514, copyright 2000.85 (B) Atomic force microscopic image of CpG-B ODN conjugated with Tat-derived peptide. Nanoring structure of CPG-B (K3) ODN conjugated with Tat-derived peptide (1:16) (a) and three-dimensional topography image of the nanoring (b). (B) From Gungor B, Yagci FC, Tincer G, et al. CPG ODN nanorings induce IFN $\alpha$ from plasmacytoid dendritic cells and demonstrate potent vaccine adjuvant activity. Sci Transl Med. 20I4;6:235ra6I. Reproduced with permission from AAAS. Copyright (C) 2014, American Association of Pharmaceutical Scientists..$^{90}$

Abbreviations: $C_{P G}$ ODN, cytosine-guanine dinucleotide-containing oligodeoxynucleotide; OVA, ovalbumin. 
the tumor size was reduced through the action of OVAspecific CTLs. ${ }^{85}$

Suzuki et $\mathrm{al}^{86}$ prepared a conjugate bonded with a thiolated CpG-B ODN by modifying the Japanese cedar pollen allergen Cryj2 T-cell epitope peptide with SMCC. In mice vaccinated with this conjugate, the secretion levels of IL-4, IL-5, and Cryj2-specific IgE were reduced, but the secretion levels of IgG2a, IgG2b, and IFN- $\gamma$ were not increased. Furthermore, when this conjugate was injected into mice that were subjected to a Cryj 2 nasal challenge, the mice showed improvement in allergic symptoms such as sneezing and nasal rubbing. In this study, an increase of IFN- $\gamma$, IgG2a, and IgG2b was not observed with the Cryj2 T-cell epitope peptide and CpG-B ODN conjugate, but an increase in IFN- $\gamma$, IgG2a, and $\mathrm{IgG} 2 \mathrm{~b}$ was found in studies on a conjugate injection of another cedar pollen allergen Cryj 1 and CpG-B ODN, which demonstrated activation of Th1-biased responses. ${ }^{87}$

In addition to the high cost associated with the chemical conjugation of $\mathrm{CpG}$ ODNs to antigens or allergens, the immunostimulatory properties may be changed through structural changes in the antigen by the synthesis process. ${ }^{88}$ Shirota and Klinman ${ }^{89}$ bonded amino-modified CpG-B ODNs to proteins on the surface of apoptotic tumor cells using the water-soluble cross-linking agent bis(sulfosuccinimidyl) suberate. In this instance, the apoptotic tumor cells play the same role as whole inactivated vaccine. When this inactivated cell-based vaccine conjugate was administered to mice, it induced the expression of costimulatory molecules in DCs and secretion of immunostimulatory cytokines. As a result, tumor-specific CTLs were activated, which led to a reduction in tumor size and prevention of metastatic spread.

Another important characteristic evident in CpG ODNs bonded to cationic proteins/peptides through electrostatic interaction is the action conversion of the CpG-B ODN. This implies that the complexes are formed when the proinflammatory cytokine inducer CpG-B ODN is bonded through electrostatic interaction to a cationic protein/peptide become type I IFN inducers. In the case of complexes composed of 12 nt CpG-B ODNs bonded through electrostatic interaction to a HIV transactivator of transcription (Tat)-derived peptide (net charge of $+8 \mathrm{mV}$ ) and a human cathelicidin derived-antimicrobial peptide (LL-37, net charge of $+6 \mathrm{mV}$ ), the size and zeta potential of the complexes were dependent upon the molecular ratio of the $\mathrm{CpG}-\mathrm{B}$ ODN to these cationic peptides. There was correlation between the level of IFN- $\alpha$ secreted from PBMCs because of these complexes and the zeta potential of the complex; the higher the positive charge density, the higher was the IFN- $\alpha$ induction level. ${ }^{90}$
The highest IFN- $\alpha$ inducer was a complex of CpG-B ODN and Tat-derived peptide, prepared with a molecular ratio of 1:16 and having a zeta potential of $\sim 40 \mathrm{mV}$. This complex had a nanoring structure, with segment particles $\sim 40 \mathrm{~nm}$ in diameter arranged in a doughnut shape (Figure 2B). The complexes with other molecular ratios were granuliform or a mixture of nanoring and particles. When a conjugate with a nanoring structure was administered to mice with the foot and mouth disease (FMD) virus vaccine, a high level of FMD virus-specific IgG2a/IgG1 was maintained, even after 6 months, which suggests Th1-mediated responses. Furthermore, when a nanoring-structured complex was administered to mice with OVA-expressing EG7 thymoma tumors, the OVA-specific Th1-mediated responses were activated and tumor growth was inhibited through activation of OVA-specific CTLs.

A surprising finding in these types of conjugates is that the IFN- $\alpha$ induction mediated by TLR 9 in $\mathrm{pDCs}$ is independent of $\mathrm{CpG}$, when double-stranded natural phosphodiester DNA is bound by electrostatic interaction to cationic peptides such as LL-37. ${ }^{32}$ This type of TLR9-mediated IFN- $\alpha$ induction, independent of $\mathrm{CpG}$, was also observed in complexes of double-stranded natural phosphodiester DNA and human $\beta$-defensin-3 or penetratin, but it was not observed in complexes with Tat-derived peptides. ${ }^{33}$ Small-angle X-ray scattering measurements showed that the DNA is organized into a columnar arrangement within all complexes. However, in complexes that induce IFN- $\alpha$, the first diffraction peak appears at $1.8-2 \mathrm{~nm}^{-1}$, compared with the first peak position at $2.48 \mathrm{~nm}^{-1}$ for Tat-derived peptides and DNA complexes. ${ }^{33}$ Based on these results, the inter-DNA spacing within complexes that induce IFN- $\alpha$ is up to $3.5 \mathrm{~nm}$, which is larger than the inter-DNA spacing (up to $2.9 \mathrm{~nm}$ ) within Tatderived peptides and DNA complexes. This suggests that the inter-DNA spacing influences the interaction between DNA and TLR9. Furthermore, this also suggests that the requisite size of cationic proteins/peptides used to form complexes with inter-DNA spacing suitable for TLR9 activation must be $0.5-2 \mathrm{~nm}$. These findings may also be useful in the development of $\mathrm{CpG}$ ODNs and protein/peptide complexes and complexes of $\mathrm{CpG}$ ODNs with other nanomaterials.

\section{Nanomaterials-based CpG ODN nanomedicines}

Nanomaterials-based $\mathrm{CpG}$ ODN nanomedicines can be divided into the type where $\mathrm{CpG}$ ODN is encapsulated within nanomaterials and the type where CpG ODN is bound to the surface of nanomaterials. 

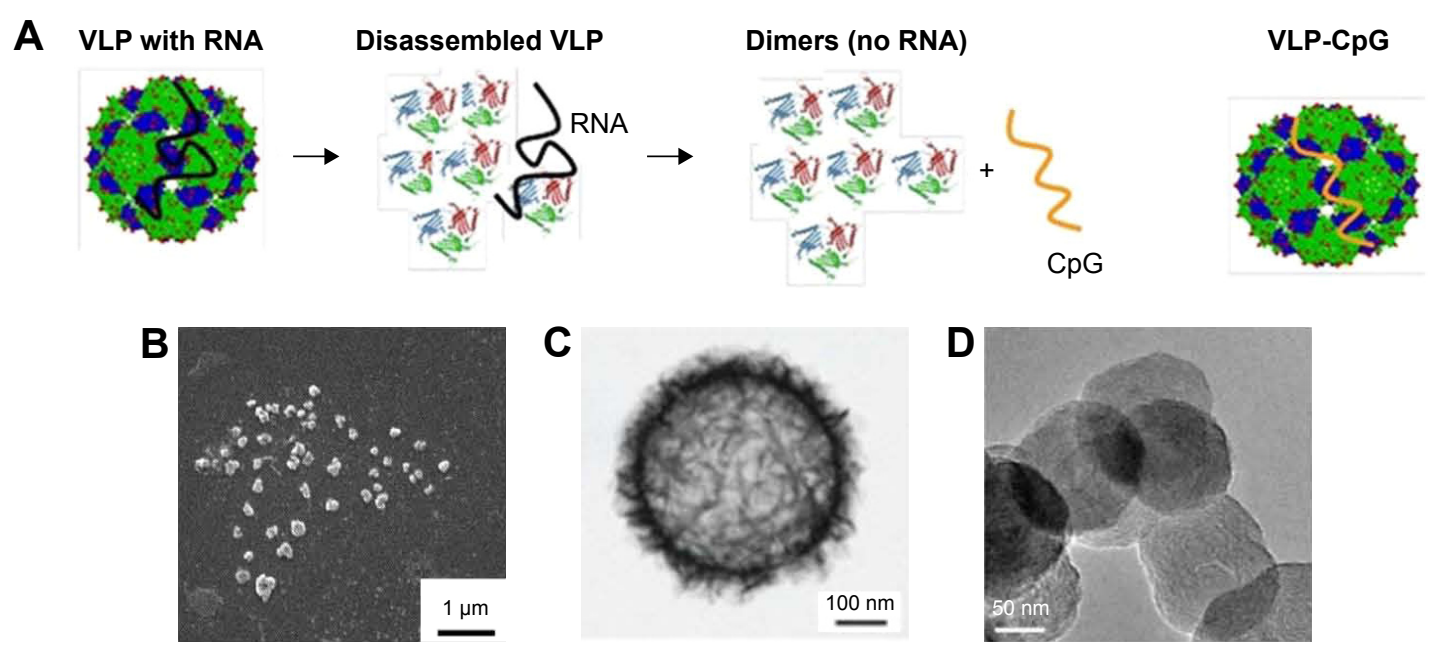

Figure 3 Nanomaterials-based CPG ODN nanomedicines.

Notes: (A) Preparation of virus-like particles (VLPs) with CG motifs ( $\left.C_{p} G s\right)$. VLPs are disassembled, and the RNA is removed. The VLPs are finally reassembled in the presence of CPG GI0. Adapted from Kundig TM, Klimek L, Schendzieloz P, Renner WA, Senti G, Bachmann MF. Is the allergen really needed in allergy immunotherapy? Curr Treat Options Allergy. 2015;2(I):72-82.98 (B) Scanning electron micrograph of chitosan/CpG ODN nanoparticles synthesized by a novel microfluidic method. Adapted from Chen S, Zhang $\mathrm{H}$, Shi $\mathrm{X}, \mathrm{Wu} \mathrm{H}$, Hanagata N. Microfluidic generation of chitosan/CpG oligodeoxynucleotide nanoparticles with enhanced cellular uptake and immunostimulatory properties. Lab Chip. 2014; I4(I I): 1842-1849 with permission from The Royal Society of Chemistry. ${ }^{104}$ Scale bar $=1 \mu \mathrm{m}$. (C) Scanning electron micrograph of flake-shell SiO 2 nanoparticle; Scale bar $=100 \mathrm{~nm}$. Copyright (C) 2012. Dove Medical Press. Adapted with permission from Manoharan Y, Ji Q, Yamazaki T, et al. Effect of molecular weight of polyethyleneimine on loading of CPG oligodeoxynucleotides onto flake-shell silica nanoparticles for enhanced TLR9-mediated induction of interferon- $\alpha$. Int J Nanomed. 2012;7:3625-3635. ${ }^{105}$ (D) Transmission electron microscopy image of the boron nitride nanosphere. Scale bar $=50 \mathrm{~nm}$. Copyright $@ 2015$. Dove Medical Press. Adapted with permission from Zhang H, Feng S, Yan T, Zhi C, Gao X-D, Hanagata N. Polyethyleneimine-functionalized boron nitride nanospheres as efficient carriers for enhancing the immunostimulatory effect of CPG oligodeoxynucleotides. Int J Nanomed. 20I5; 10:5343-5353.106

Abbreviations: CPG ODN, cytosine-guanine dinucleotide-containing oligodeoxynucleotide; PLGA, poly(lactic-co-glycolic acid); CG, cytosine-guanine; OVA, ovalbumin.

Biodegradable poly(lactic-co-glycolic acid) (PLGA) is a polymer approved by the US Food and Drug Administration, rendering it as one of the candidate materials for $\mathrm{CpG}$ ODN formulation in clinical application. Joshi et al ${ }^{91}$ encapsulated CpG-B ODNs in PLGA particles using the double emulsion solvent evaporation method, where the particles were separated into three average sizes of $300 \mathrm{~nm}, 1 \mu \mathrm{m}$, and $9.2 \mu \mathrm{m}$ depending upon differences in the sedimentation conditions of the centrifugation. They investigated the therapeutic effect on house dust allergies based on the differences in the size of PLGA particles, when the surface of these particles was coated with the house dust mite allergen Der $\mathrm{p} 2$. PLGA particles coated with Der $\mathrm{p} 2$ and the encapsulated $\mathrm{CpG}-\mathrm{B}$ ODN were administered twice to mice, and then intranasal instillation of Der $\mathrm{p} 2$ was performed for 10 days to induce airway inflammation and hyperresponsiveness. All three sizes of PLGA particles inhibited airway hyperresponsiveness, but the percentage of eosinophils in bronchoalveolar lavage fluids and the ratio of Der p2-specific IgG2a and IgG1 (IgG2a/IgG1) were higher with the $300 \mathrm{~nm}$ and $1 \mu \mathrm{m}$ PLGA particles than with the $9.2 \mu \mathrm{m}$ particles. Conversely, Der p2-specific IgE titers were higher with the $9.2 \mu \mathrm{m}$ PLGA particles. Based on these results, the prophylactic effect on house dust allergy is dependent on the size of the PLGA particles, and the results demonstrated that a high level of efficacy can be expected with particles of $1 \mu \mathrm{m}$ or less. Furthermore, even with both OVA and CpG-B ODN encapsulated with the PLGA particles, OVA-specific IgG2a/IgG1 levels were higher with particles of $1 \mu \mathrm{m}$ or less, ${ }^{92}$ and it was demonstrated that irrespective of whether antigens (or allergens) are on the surface of or inside the PLGA particles, activation of Th1-biased responses was dependent on the particle size. Moreover, OVA-specific CTLs were activated with the $300 \mathrm{~nm}$ PLGA particles encapsulating both OVA and CpG-B ODN, implying that these complexed nanoparticles are effective as immunotherapy for both infections and cancers. Nikitczuk et $\mathrm{al}^{93}$ investigated the preventative and therapeutic effects of PLGA particles with a mean diameter of $\sim 500 \mathrm{~nm}$, encapsulating OVA and CpG-B ODN, on E.G7OVA tumors. These PLGA particles were injected twice into mice at 2 weeks apart. Then, 7 days later, the mice were subjected to a tumor cell challenge and the tumor size and survival rate were investigated. The results showed that in mice preadministered with complexed PLGA particles, there was inhibition of tumor growth and a higher survival rate than in nontreated mice. This showed that the PLGA particles encapsulating the antigen and CpG-B ODN have a preventative effect on tumor formation. Furthermore, when the PLGA particles were intratumorally injected into tumors that had already formed, marked inhibition of tumor growth and high 
survival rate were observed, thus confirming the therapeutic effect of PLGA particles encapsulating OVA and CpG-B ODN. In these mice, the OVA-specific Th1 responses were activated by the complexed PLGA particles, but there was no increased activation of OVA-specific CTLs, indicating that tumor growth inhibition could be due to Th1 responses. Although PLGA particles with a mean diameter of $500 \mathrm{~nm}$ encapsulating OVA and CpG-B ODN did not increase the activation of OVA-specific CTLs, ${ }^{93}$ in the study by Joshi et al, ${ }^{92}$ PLGA particles with a mean diameter of $300 \mathrm{~nm}$ encapsulating CpG-B ODN did increase the activation of OVA-specific CTLs. Joshi et $\mathrm{al}^{92}$ reported that the activation of OVA-specific CTLs was dependent upon the size of the PLGA particles; however, whether a difference in the mean diameter (ie, $300 \mathrm{~nm}$ vs $500 \mathrm{~nm}$ ) alone is enough to affect CTL activation is unknown.

Hepatitis B virus (HBV) is the known causative agent of hepatitis $B$ infection. Lv et $\mathrm{a}^{94}$ investigated the effect of HBV-based CpG ODNs on humoral and cellular immunity. The CpG ODN was designed on the basis of arrangements of the $\mathrm{CpG}$ islands in the HBV genome, and encapsulated in particles with a mean diameter of $120 \mathrm{~nm}$, prepared using the double emulsion solvent evaporation method with a polyethylene glycol (PEG) and polylactic acid (PLA) diblock copolymer and the cationic lipid N,N-bis(2-hydroxyethyl)$N$-methyl- $N$-(2-cholesteryloxycarbonyl aminoethyl) ammonium bromide. When these cationic lipid-assisted PEG-PLA nanoparticles were administered to mice with the hepatitis B surface antigen, there was significant activation of the Th1biased antibody response, and antigen-specific IgG2a was induced. The expression of CTL CD69 was also upregulated. Furthermore, these nanoparticles induced efficient clearance of HBV in HBV carrier mice. These observations suggest that it may be possible to treat hepatitis B with $\mathrm{CpG}$ ODNs encapsulated in cationic lipid-assisted PEG-PLA nanoparticles.

Compelling findings have been obtained on the therapeutic effect of virus-like nanoparticle-encapsulated $\mathrm{CpG}-\mathrm{A}$ ODNs on allergic asthma. The bacteriophage $Q \beta$ capsid protein can be expressed in large quantities within Escherichia coli through genetic recombination technology. When this recombination capsid protein is disassembled in a reducing condition and reassembled in the presence of $\mathrm{CpG}-\mathrm{A}$ ODNs, the CpG-A ODN can be encapsulated in the capsid (Figure 3A). Although both the $\mathrm{CpG}$ ODN and the antigen can be encapsulated in this virus-like nanoparticle, it is also possible to bind the antigen to the surface of the virus-like nanoparticle with heterobifunctional cross-linkers such as succinimidyl-6-( $\beta$-maleimidopropionamide) hexanoate. ${ }^{92}$
In a clinical study where melanoma-specific Melan A peptides were bound to the surface of $Q \beta$-derived virus-like nanoparticles encapsulating $\mathrm{CpG}-\mathrm{A}$ ODN and then administered to 22 patients with stage I-IV melanomas, it was reported that this virus-like nanoparticle complex induced Melan A-specific CTLs in 14 patients. ${ }^{95}$ Additionally, in a clinical study where this same $\mathrm{Q} \beta$-derived nanoparticle complex was administered with the house dust mite allergen to patients with a house dust allergy, the allergen-specific IgG increased in these patients, while allergen-specific IgE decreased, resulting in improvement in the symptoms of allergic rhinitis and asthma. ${ }^{96}$ This effect was also observed in patients with mild-to-moderate persistent allergic asthma who had stopped administration of glucocorticosteroids. ${ }^{97}$ Furthermore, even when the Q $\beta$-derived nanoparticle complex was administered without the allergen, there was a clear therapeutic effect on patients with house dust allergy. ${ }^{98}$ This shows that in the treatment of house dust allergy, it is not necessary to administer the allergen, as the Q $\beta$-derived nanoparticle complex suffices to give a therapeutic effect. The reason that the allergen is not necessary is likely because the house dust mite is present everywhere throughout the seasons, so the allergen is naturally acquired from the environment. Administration of the $\mathrm{Q} \beta$-derived nanoparticle complex alone makes it possible to avoid the risk of anaphylactic shock to the allergen, making it possible to improve the safety of the treatment. However, just recently, there was a report that administration of this same $Q \beta$-derived nanoparticle complex resulted in no therapeutic improvement in patients with persistent moderate-to-severe allergic asthma. ${ }^{99}$ Therefore, the efficacy of this particular nanomedicine may only apply to patients with controlled mild-to-moderate persistent allergic asthma undergoing glucocorticosteroid withdrawal.

The prophylactic and therapeutic effects of $\mathrm{pH}$-sensitive liposomes, coencapsulating CpG ODN and TAA, on cancer have been reported. Kwon et al ${ }^{100}$ coencapsulated a $20 \mathrm{nt}$ phosphodiester $\mathrm{CpG}$ ODN and a tumor-specific antigen (TM4SF5R2-3) in a pH-sensitive liposome composed of phosphatidyl- $\beta$-oleoyl- $\gamma$-palmitoyl ethanolamine (POPE) and cholesterol hemisuccinate (CHEMS). The liposome was administered three times to mice at 10-day intervals, and mouse hepatoma BNL-HCC cells were inoculated under the skin on the back of the mice 90 days after the initial dose. The growth of the formed tumor cells was markedly inhibited with advance administration of the liposome coencapsulating $\mathrm{CpG}$ ODN and tumor-specific antigen, and as a result, the survival rate improved. Likewise, in mice inoculated with colon cancer CT-26 cells under the skin on 
the back and then administered the liposome three times at 7-day intervals, the tumor growth was inhibited and the survival rate of the mice improved. ${ }^{101}$ The prophylactic and therapeutic effects of the liposome coencapsulating $\mathrm{CpG}$ ODNs and tumor-specific antigens on cancer are suggested to be caused by the induction of long-term memory B cells and production of antigen-specific antibodies. Liposomes composed of POPE and CHEMS are $\mathrm{pH}$-sensitive, so they become unstable within endosomes in acidic environments, and thereby the antigen is released into the cytosol. If this is the case, then the antigen is presented even on MHC-I molecules, so antigen-specific CTLs may also be involved in the inhibition of tumor growth.

It has been reported that the liposome surface charge influences the adjuvant effect of the encapsulated CpG-A ODN. ${ }^{102}$ In DCs present in the spleens of mice injected with neutral, anionic, and cationic liposomes (larger than $150 \mathrm{~nm}$ and encapsulating CpG-A ODNs), the expression of CD86 was the highest with the anionic liposome. When these liposomes encapsulating $\mathrm{CpG}-\mathrm{A}$ ODNs were injected together with OVA, the IgG2a production level was the highest with the anionic liposome. The fluidity of the liposome membrane is not thought to influence immune activation, so these results suggest that the surface charge of the liposomes could affect immune activation.

The administration route also seems to influence the adjuvant effect of liposomes encapsulating $\mathrm{CpG}$ ODNs. Slutter et $\mathrm{al}^{103}$ prepared liposomes with a mean diameter of $260 \mathrm{~nm}$ encapsulating CpG-B ODN and OVA. These liposomes were made from soybean phosphatidylcholine (PC), 1,2-dioleoyl3 -trimethylammoniumpropane chloride salt (DOTAP), and 1,2-dioleoyl-sn-glycero-3-phosphoethanolamine (DOPE) (PC:DOTAP:DOPE =9:1:1 molar ratio), and the zeta potential was $18 \mathrm{mV}$. When these liposomes were administered to mice using intranodal, intradermal, transcutaneous, and nasal administration routes, a high production of OVA-specific IgG2a was observed with intranodal and intradermal administration, whereas only a very small amount of $\mathrm{IgG} 2 \mathrm{a}$ was produced with transcutaneous administration. OVA-specific IgG2a was also produced with nasal administration, but the production level was lower than when nonliposome-involved free OVA and CpG-B ODN were administered nasally. There are numerous reports that the immunomodulatory effect is enhanced through nasal administration of nanoparticles complexed with CpG ODNs, so the effect with intranasal administration may be dependent upon the CpG ODN conjugation method.

It is possible to prepare particles encapsulating $\mathrm{CpG}$ ODNs using the polycation and $\mathrm{CpG}$ ODN bulk mixing method, but it is difficult to control the size of the particles with this method. Chen et al ${ }^{104}$ prepared highly uniform nanoparticles with a mean size of $\sim 200 \mathrm{~nm}$, made from chitosan and CpG-B ODNs, using the microfluidic method (Figure 3B). Adjusting the channel flow rate of various microfluidic devices enabled control of the particle size, zeta potential, and CpG ODN loading capacity, and so the microfluidic method could be applied to formation of complexes with polycations other than CpG ODN and chitosan. However, the disadvantage of the microfluidic method is that it is difficult to prepare large amount of complexed nanoparticles.

In complexes where the $\mathrm{CpG}$ ODN is bound to the surface of nanomaterials, it has been reported that the binding method affects the induction of cytokines. ${ }^{29}$ When a CpG-B ODN formed from a phosphodiester backbone was bound through electrostatic interaction to the surface of silicon nanoparticles with a mean diameter of $3.4 \mathrm{~nm}$ and given a positive charge through modification with allylamine, this complex induced IFN- $\alpha$ from PBMCs. Maleimide groups were induced when the same silicon nanoparticle surfaces were modified with SMCC, and a complex bound with CpG-B ODN with a thiol group inserted on the $3^{\prime}$ end did not induce IFN- $\alpha$, but instead induced inflammatory cytokines such as IL-6 and TNF- $\alpha$. The negative charge on the DNA molecule is derived from the nucleotide phosphate groups; thus, in binding through electrostatic interaction, the entire CpG-B ODN molecule is thought to bind to the silicon nanoparticle. Conversely, when the CpG-B ODN 3'-end thiol group binds with the maleimide group on the surface of the nanoparticle, only the CpG-B ODN 3' end binds with the surface of the nanoparticle, and the $5^{\prime}$ end is free. No release of CpG-B ODNs from the silicon nanoparticles was observed with either binding method, which suggests that the method of binding CpG-B ODNs to the surface of the nanoparticle has significant influence on bifurcated cytokine induction.

One other study has also suggested that the differences in the methods of binding CpG-B ODN to the surface of the nanoparticle influence cytokine induction. Complexes where the surfaces of flake-shell silica nanoparticles (Figure 3C) were coated with the polycation polyethyleneimine (PEI) and $\mathrm{CpG}-\mathrm{B}$ ODN, bound through electrostatic interaction, induced IFN- $\alpha$ from PBMCs, and it was reported that the induction level was dependent on the mean molecular weight of PEI. ${ }^{105}$ Flake-shell silica nanoparticles coated with PEI of $600 \mathrm{Da}$ were observed to induce a higher level of IFN- $\alpha$ than those coated with PEI of 1,800 and 10,000 Da. It has been suggested that this phenomenon is due to the shortening of the retention time in the nanoparticles endosome and the proton 
sponge effect in PEIs with greater molecular weight. The surface area of flake-shell silica nanoparticles is 83 times larger than nanoparticles of the same size with a smooth surface. Enlarging the surface area means that the loading amount of CpG ODN can also be increased. In the same way, induction of IFN- $\alpha$ was observed with complexes where CpG-B ODN was bound through electrostatic interaction to boron nitride nanoparticles (Figure 3D) coated with PEI of 600 Da, even with stimulation of the PBMCs. ${ }^{106}$ An exception to this rule was with complexes where the CpG-B ODN was bound through electrostatic interaction to boron nitride nanoparticles coated with the polycation chitosan, which lacked the capability of inducing IFN- $\alpha{ }^{107}$ This is thought to be because chitosan inhibited the induction of IFN- $\alpha$.

Chinnathambi et $\mathrm{al}^{30}$ prepared silicon nanoparticles with different positive surface charge densities, and bound CpG-B ODNs to the particles through electrostatic interaction. When PBMCs were stimulated with these complexes, IFN- $\alpha$ induction was dominant in the case of CpG-B ODNs bound to nanoparticles with a large positive surface charge density, whereas induction of proinflammatory cytokines such as IL-6 was dominant in the case of CpG-B ODNs bound to nanoparticles with a small positive surface charge density. This suggests that binding of $\mathrm{CpG}-\mathrm{B}$ ODNs to cationic nanoparticles through electrostatic interaction influences the induction of bifurcated cytokines. When Xu et al ${ }^{108}$ stimulated RAW264.7 cells with a complex in which the $\mathrm{CpG-B}$ ODN was bound to the surface of aminated mesoporous silica nanoparticles through electrostatic interaction, the nanoparticles with fewer amino groups on the surface (ie, nanoparticles with a smaller positive surface charge density) induced a higher level of proinflammatory cytokines.

Conversely, when RAW264.7 cells were stimulated with complexes where the 3 '-end thiolated CpG-B ODN was bound to the surface of gold nanoparticles, or when PBMCs were stimulated with complexes where the CpG-B ODN with a boron nitride-specific binding peptide inserted at the 3 ' end was bound to the surface of boron nitride nanoparticles mediated by the peptide, proinflammatory cytokines such as TNF- $\alpha$ and IL-6 were induced. ${ }^{109,110}$ These results show that when only one terminus of CpG-B ODN is bound to the surface of the nanoparticle, proinflammatory cytokines are induced rather than IFN- $\alpha / \beta$, in the same way as with complexes where thiolated CpG-B ODN is bound to the surface of maleimide-functionalized nanoparticles.

By binding only one terminus of the CpG ODN to the surface of the nanomaterial with a cleavable disulfide bond, it is possible to release the $\mathrm{CpG}$ ODN in response to the reductive condition within the endosome. Ballester et $\mathrm{al}^{111}$ investigated the prophylactic and therapeutic effects of complexes on house dust allergies, where the thiolated CpG-B ODN was bound to pyridyl disulfide-functionalized poly(propylene sulfide) nanoparticles measuring $\sim 30 \mathrm{~nm}$. The complex was administered three times to mice every 2 days through intranasal instillation. When the mice underwent sensitization and were subjected to house dust mite challenge, the IgE production in the lungs was suppressed and the eosinophil count also decreased. Furthermore, the production of cytokines that induce Th2-biased immunity, such as IL-4 and IL-5, was inhibited in the lungs, which suggested the prophylactic effect of the complex on allergies. After sensitization with house dust mite, the complex was administered by intranasal instillation and the mice underwent a further house dust mite challenge. The level of IgE produced and the eosinophil count were inhibited in the lungs of these mice, which suggested a prophylactic effect on allergies. This inhibition was also seen in mice administered free (noncomplexed) $\mathrm{CpG}-\mathrm{B}$ ODNs through intranasal instillation; however, production of IL-4, IL-5, and IL-13 in the lungs was significantly more inhibited with the administration of the complex, compared with the administration of free CpG-B ODNs. This result means that the $\mathrm{CpG}-\mathrm{B}$ ODN complex has a greater therapeutic effect than free CpG-B ODNs through inhibition of the Th2-biased response. Jeanbalt et $\mathrm{al}^{112}$ prepared a complex where a thiolated CpG-B ODN was bound to pyridyl disulfide-functionalized poly(propylene sulfide) nanoparticles, and another complex where TAA was bound to these nanoparticles. These complexes were administered to the front footpad of mice that had a tumor on the left side of the back only. When these complexes were administered to the left front footpad, the local and systemic CTL responses were stronger than when the complex was administered to the right front footpad, which in turn enhanced tumor regression and host survival. This is thought to be because administering the complexes on the same side as the tumor enabled more effective delivery of CpG-B and TAA to the antigen-presenting cells of the tumordraining lymph node. A therapeutic effect on brain tumors has been reported for complexes where one terminus of $\mathrm{CpG}-\mathrm{B}$ ODN was bound to a 200-400 nm long single-walled carbon nanotube (SWCNT) through a cleavable disulfide bond, and the SWCNT had been modified with phospholipid-PEG and sulfo-LC- $N$-succinimidyl-3-(2-pyridyldithio) propionate. ${ }^{113}$ When the SWCNT-CpG-B complex was administered to mice that had undergone intracranial implantation of glioma cells, there was greater inhibition of tumor growth and a higher survival rate compared with the administration of free 
CpG-B ODNs. These results suggest that complexation with SWCNTs improves the efficiency of CpG-B ODN uptake and causes activation of CTLs and NK cells.

\section{Problem areas in the development of CpG ODN nanomedicines}

Recent studies on $\mathrm{CpG}$ ODN nanomedicines were reviewed in this article. However, not all $\mathrm{CpG}$ ODN nanomedicines are superior to free $\mathrm{CpG}$ ODNs in immunostimulatory capacity. For instance, the induction level of IFN- $\alpha$ in the nanoringstructured complex of CpG-B ODN with Tat-derived peptide was similar to that of free CpG-A ODN in human PBMCs. ${ }^{90}$ Although the induction level of IFN- $\alpha$ in the nanoringstructured complex did not show greater potential than free $\mathrm{CpG}-\mathrm{A}$ ODN, the nanoring-structured complex has an advantage. This implies that the nanoring-structured complex has a narrow size distribution, ${ }^{90}$ whereas free CpG-A ODN forms uncontrolled higher order structures of various sizes by self-assembly, ${ }^{18,19}$ which makes it impossible to provide free CpG-A ODN for clinical application.

The largest concern with the clinical application of $\mathrm{CpG}$ ODN nanomedicines is safety. It is particularly vital to carefully assess the safety of nanomaterials in nanomaterialbased CpG ODN nanomedicines. In humans, only pDCs and B cells express TLR9. However, there are virtually no CpG ODN nanomedicines with the capability of targeting these cell types. Therefore, it is essential to assess the safety of CpG ODN nanomedicines taken up by cell types that express TLR9 as well as those taken up by cell types that do not express TLR9. Self-assembled CpG ODNs and antigen/ allergen-CpG ODN conjugates do not use nanomaterials, so it is thought that these substances can avoid most of the safety issues associated with nanomaterials. However, multiple ODNs are synthesized with self-assembled $\mathrm{CpG}$ ODNs and it is necessary to ensure precise self-association, which makes the high cost and complexity of the operations problematic. Moreover, in conjugates where the $\mathrm{CpG}$ ODN is covalently bonded with antigens or allergens, the structure of the antigens or allergens may be altered through the reaction operations. There are advantages and disadvantages to each of the self-assembled CpG ODN nanomedicines, protein/ peptide-CpG ODN conjugates, and nanomaterials-based CpG ODN nanomedicines, and so it is vital to develop $\mathrm{CpG}$ ODN nanomedicines taking all of the advantages and disadvantages into due consideration.

One more problem in development aiming for the clinical application of CpG ODN nanomedicines is that the cell types that express TLR9 differ in mice and in humans.
TLR9 is expressed only on pDCs and B cells in humans, but in mice, in addition to these cell types, it is expressed on macrophages and myeloid DCs. Therefore, there is no evidence that the effect of $\mathrm{CpG}$ ODN nanomedicines obtained in mouse models can be reproduced in humans. The results obtained in mouse models provide data for clinical trials in humans, but that information is not absolute. It is necessary to be aware of this issue when progressing from preclinical studies to clinical trials.

\section{Prospects for the future}

All the CpG-B ODNs for which clinical trials have been conducted or are in progress have been constructed with a phosphorothioate backbone, to provide resistance to degradation by DNase. However, as mentioned previously, there are various adverse drug reactions that are a cause for concern with phosphorothioated DNA. In a recent preclinical study, major liver damage and spleen damage were observed in mice administered a CpG-B ODN (ODN1826). ${ }^{75}$ Moreover, in the Phase III clinical trial in which a CpG-B ODN (PF-3512676, also known as ODN2006 or CpG-7909) was combined with standard chemotherapy, it was reported that patients administered with the CpG-B ODN had a high probability of developing adverse events. ${ }^{114,115}$ The results of these preclinical and clinical studies suggest that $\mathrm{CpG}$ ODNs with a phosphodiester backbone would be preferable to those with a phosphorothioate backbone. CpG ODNs with a phosphodiester backbone can provide DNase resistance in the self-assembled $\mathrm{CpG}$ ODNs, protein/peptide-CpG ODN conjugates, and nanomaterial-CpG ODN complexes. In particular, self-assembled $\mathrm{CpG}$ ODNs can be prepared with phosphodiester CpG ODNs only, without using proteins/ peptides and nanomaterials, so this is considered to be a major advantage in terms of safety. If the aforementioned issues with the complexity of operations for manufacture and the manufacturing costs can be improved, the self-assembled CpG ODNs could be a promising adjuvant. Furthermore, if it is possible to assert the safety of the protein/peptide and nanomaterial, then complexes of phosphodiester backbonebased CpG ODNs with proteins/peptides or nanomaterials would open up the path to clinical application. Utilizing the merits of being able to use phosphodiester $\mathrm{CpG}$ ODNs rather than phosphorothioated CpG ODNs in CpG ODN nanomedicines is considered to be one direction for the development of this therapy.

CpG-A ODNs form a variety of higher ordered structures under physiological conditions, which are recognized by TLR9 and can induce type I IFN. Although CpG-A ODN 
activates CTLs, which makes it an attractive adjuvant, the difficulty in controlling the formation of uniform higher ordered structure is hindering approval for its clinical application. However, by forming complexes between CpG-B ODN, a proinflammatory cytokine inducer, and a cationic protein/peptide and/or cationic nanomaterial using electrostatic interactions, the CpG-B ODN can be converted to a type I IFN inducer, similar to CpG-A ODNs. If the size of these complexes can be uniformly controlled, it may mean that these complexes could be used in clinical application as an adjuvant that induces type I IFN. The development of uniformly sized complexes with natural phosphodiester $\mathrm{CpG}$ ODNs and cationic protein/peptides or cationic nanomaterials is considered to be an important issue for CpG ODN nanomedicines.

CpG ODN nanomedicines that have undergone clinical trials include the dumbbell-like CpG ODN (MGN1703), CpG ODN-conjugated ragweed allergen, and $\mathrm{Q} \beta$-derived viruslike nanoparticle encapsulating CpG-A ODN, but almost all the clinical trials to date have been conducted with free $\mathrm{CpG}$ ODNs only. As introduced earlier in this review, many preclinical studies suggest that $\mathrm{CpG}$ ODN nanomedicines have higher prophylactic and therapeutic effects on cancers, infectious diseases, and allergies compared to free CpG ODNs. Thus, we are now anticipating that further development in the research into $\mathrm{CpG}$ ODN nanomedicines will mean progression to clinical trials and the appearance of many new $\mathrm{CpG}$ ODN nanomedicines, and we are also awaiting the evidence for efficacy of this medicine in humans.

\section{Disclosure}

The author reports no conflict of interest in this work.

\section{References}

1. Hemmi H, Takeuchi O, Kawai T, et al. A Toll-like receptor recognizes bacterial DNA. Nature. 2000;408:740-745.

2. Takeshita F, Leifer CA, Gursel I, et al. Cutting edge: role of toll-like receptor 9 in CpG DNA-induced activation of human cells. J Immunol. 2001;167(7):3555-3558.

3. Gursel M, Verthelyi D, Gursel I, Ishii KJ, Klinman DM. Differential and competitive activation of human immune cells by distinct classes of CpG oligodeoxynucleotides. J Leukoc Biol. 2002;71(5): $813-820$.

4. Hornung V, Rothenfusser S, Britsch S, et al. Quantitative expression of toll-like receptor 1-10 mRNA in cellular subsets of human peripheral blood mononuclear cells and sensitivity to $\mathrm{CpG}$ oligodeoxynucleotides. J Immunol. 2002;168(9):4531-4537.

5. Kadowaki N, Ho S, Antonenko S, et al. Subsets of human dendritic cell precursors express different Toll-like receptors and respond to different microbial antigens. J Exp Med. 2001;194(6):863-869.

6. Krug A, Towarowski A, Britsch S, et al. Toll-like receptor expression reveals CpG DNA as a unique microbial stimulus for plasmacytoid dendritic cells which synergizes with CD40 ligand to induce high amounts of IL-12. Eur J Immunol. 2001;31(10):3026-3037.
7. Bauer M, Redecke V, Ellwart JW, et al. Bacterial CpG DNA triggers activation and maturation of human CD11c(-), CD123(+) dendritic cells. J Immunol. 2001;166(8):5000-5007.

8. Bode C, Zhao G, Steinhagen F, Kinjo T, Klinman DM. CpG DNA as a vaccine adjuvant. Expert Rev Vaccines. 2011;10(4):499-511.

9. Shirota H, Klinman DM. Recent progress concerning CpG DNA and its use as a vaccine adjuvant. Expert Rev Vaccines. 2014;13(2):299-312.

10. Krieg AM. CpG motifs in bacterial DNA and their immune effects. Annu Rev Immunol. 2002;20:709-760.

11. Gürsel M, Verthelyi D, Gürsel I, Ishii KJ, Klinman DM. Differential and competitive activation of human immune cells by distinct classes of CpG oligonucleotide. J Leukoc Biol. 2002;71(5):813-820.

12. Hartmann G, Weeratna RD, Ballas ZK, et al. Delineation of a CpG phosphorothioate oligodeoxynucleotide for activating primate immune responses in vitro and in vivo. J Immunol. 2000;164(3):1617-1624.

13. Hartmann G, Krieg AM. Mechanism and function of a newly identified CpG DNA motif in human primary B cells. J Immunol. 2000;164(2): 944-953.

14. Stein CA, Subasinghe C, Shinozuka K, Cohen JS. Physicochemical properties of phosphorothioate oligodeoxynucleotides. Nucleic Acids Res. 1988;16(8):3209-3221.

15. Shaw JP, Kent K, Bird J, Fishback J, Froehler B. Modified deoxynucleotides stable to exonuclease degradation in serum. Nucleic Acids Res. 1991;19(4):747-750.

16. Mutwiri GK, Nichani AK, Babiuk S, Babiuk LA. Strategies for enhancing the immunostimulatory effects of $\mathrm{CpG}$ oligodeoxynucleotides. J Control Release. 2004;97(1):1-17.

17. Krug A, Rothenfusser S, Hornung V, et al. Identification of CpG oligonucleotide sequences with high induction of IFN-alpha/ beta in plasmacytoid dendritic cells. Eur J Immunol. 2001;31(7): 2154-2163.

18. Kerkmann M, Costa LT, Richter C, et al. Spontaneous formation of nucleic acid-based nanoparticles is responsible for high interferon-alpha induction by $\mathrm{CpG}-\mathrm{A}$ in plasmacytoid dendritic cells. J Biol Chem. 2005;280(9):8086-8093.

19. Klein DC, Latz E, Espevik T, Stokke BT. Higher order structure of short immunostimulatory oligonucleotides studied by atomic force microscopy. Ultramicroscopy. 2010;110(6):689-693.

20. Sheehan JP, Lan HC. Phosphorothioate oligonucleotides inhibit the intrinsic tenase complex. Blood. 1998;92(5):1617-1625.

21. Henry SP, Novotny W, Leeds J, Auletta C, Kornbrust DJ. Inhibition of coagulation by a phosphorothioate oligonucleotide. Antisense Nucleic Acid Drug Dev. 1997;7(5):503-510.

22. Shaw DR, Rustagi PK, Kandimalla ER, Manning AN, Jiang Z, Agrawal S. Effects of synthetic oligonucleotides on human complement and coagulation. Biochem Pharmacol. 1997;53:1123-1132.

23. Brown DA, Kang SH, Gryaznov SM, et al. Effect of phosphorothioate modification of oligodeoxynucleotides on specific protein binding. J Biol Chem. 1994;269(43):26801-26805.

24. Levin AA. A review of the issues in the pharmacokinetics and toxicology of phosphorothioate antisense oligonucleotides. Biochim Biophys Acta. 1999;1489(1):69-84.

25. Henry SP, Beattie G, Yeh G, et al. Complement activation is responsible for acute toxicities in rhesus monkeys treated with a phosphorothioate oligodeoxynucleotide. Int Immunopharmacol. 2002;2(12): 1657-1666.

26. Agrawal S, Zhao Q, Jiang Z, et al. Toxicologic effects of an oligodeoxynucleotide phosphorothioate and its analogs following intravenous administration in rats. Antisense Nucleic Acid Drug Dev. 1997;7(6): 575-584.

27. Bjersing JL, Eriksson K, Tarkowski A, Collins LV. The arthritogenic and immunostimulatory properties of phosphorothioate oligodeoxynucleotides rely on synergy between the activities of the nuclease-resistant backbone and CpG motifs. Inflammation. 2004;28(1):39-51.

28. Heikenwalder M, Polymenidou M, Junt T, et al. Lymphoid follicle destruction and immunosuppression after repeated $\mathrm{CpG}$ oligodeoxynucleotide administration. Nat Med. 2004;10(2):187-192. 
29. Chinnathambi S, Chen S, Ganesan S, Hanagata N. Binding mode of CpG oligodeoxynucleotides to nanoparticles regulates bifurcated cytokine induction via Toll-like receptor 9. Sci Rep. 2012;2:534.

30. Chinnathambi S, Pi X, Xu M, Hanagata N. Regulation of bifurcated cytokine induction by surface charge of nanoparticles during interaction between $\mathrm{CpG}$ oligodeoxynucleotides and toll-like receptor 9. J Drug Deliv Sci Technol. 2015;29:251-260.

31. Haas T, Schmitz F, Heit A, Wagner H. Sequence independent interferonalpha induction by multimerized phosphodiester DNA depends on spatial regulation of Toll-like receptor-9 activation in plasmacytoid dendritic cells. Immunology. 2009;126(2):290-298.

32. Lande R, Gregorio J, Facchinetti V, et al. Plasmacytoid dendritic cells sense self-DNA coupled with antimicrobial peptide. Nature. 2007;449: 564-569.

33. Schmidt NW, Jin F, Lande R. Liquid-crystalline ordering of antimicrobial peptide-DNA complexes controls TLR9 activation. Nat Mater. 2015;14:696-700.

34. Bos R, Sherman LA. CD4 $4^{+} \mathrm{T}$-cell help in the tumor milieu is required for recruitment and cytolytic function of $\mathrm{CD} 8^{+} \mathrm{T}$ lymphocytes. Cancer Res. 2010;70(21):8368-8377.

35. Vacchelli E, Pol J, Bloy N, et al. Trial watch: tumor-targeting monoclonal antibodies for oncological indications. OncoImmunology. 2015;4(1): e985940.

36. Xie Y, Akpinarli A, Maris C. Naive tumor-specific $\mathrm{CD}^{+}{ }^{+} \mathrm{T}$ cells differentiated in vivo eradicate established melanoma. $J$ Exp Med. 2010; 207(3):651-667.

37. Braumüller H, Wieder T, Brenner E, et al. T-helper-1-cell cytokines drive cancer into senescence. Nature. 2013;494:361-365.

38. Hartmann G, Weiner GJ, Krieg AM. CpG DNA: a potential signal for growth, activation and maturation of human dendritic cells. Proc Natl Acad Sci U S A. 1999;96(16):9305-9310.

39. Jarrossay D, Napolitani G, Colonna M, Sallusto F, Lanzavecchia A. Specialization and complementary in microbial molecule recognition by human myeloid and plasmacytoid dendritic cells. Eur J Immunol. 2001;31(11):3388-3393.

40. Kerkmann M, Rothenfusser S, Hornung V, et al. Activation with CpG-A and CpG-B oligodeoxynucleotides reveals two distinct regulatory pathways of type I IFN synthesis in human plasmacytoid dendritic cells J Immunol. 2003;170(9):4465-4474.

41. Agnello D, Lankford CS, Bream J, et al. Cytokines and transcription factors that regulate $\mathrm{T}$ helper cell differentiation: new players and new insights. J Clin Immunol. 2003;23(3):147-161.

42. Kumagai Y, Takeuchi O, Akira S. TLR9 as a key receptor for the recognition of DNA. Adv Drug Deliv Rev. 2008;60(7):795-804

43. Hervas-Stubbs S, Riezu-Boj JI, Gonzalez I, et al. Effects of IFN- $\alpha$ as a signal-3 cytokine on human naïve and antigen-experienced CD8+ T cells. Eur J Immunol. 2010;40(12):3389-3402.

44. Huber JP, Farrar JD. Regulation of effector and memory T-cell functions by type I interferon. Immunology. 2011;132(4):466-474

45. Kolumam GA, Thomas S, Thompson LJ, Sprent J, Murali-Krishna K. Type I interferons act directly on CD8 T cells to allow clonal expansion and memory formation in response to viral infection. $J$ Exp Med. 2005;202(5):637-650.

46. Napolitani G, Rinaldi A, Bertoni F, Sallusto F, Lanzavecchia A. Selected Toll-like receptor agonist combinations in synergistically trigger a $\mathrm{T}$ helper type I-polarizing program in dendritic cells. Nat Immunol. 2005;6(8):769-776.

47. Roman M, Martin-Orozco E, Goodman JS, et al. Immunostimulatory DNA sequences function as T helper-1promoting adjuvants. Nat Med. 1997;3(8):849-854.

48. Ballas ZK, Rasmussen WL, Krieg AM. Induction of NK activity in murine and human cells by $\mathrm{CpG}$ motifs in oligodeoxynucleotides and bacterial DNA. J Immunol. 1996;157(5):1840-1845.

49. Shirota Y, Shirota H, Klinman DM. Intratumoral injection of $\mathrm{CpG}$ oligonucleotides induces the differentiation and reduces the immunosuppressive activity of myeloid-derived suppressor cells. J Immunol. 2012;188:1592-1599.
50. Bernasconi NL, Onai N, Lanzavecchia A. A role for Toll-like receptors in acquired immunity: up-regulation of TLR9 by BCR triggering in naïve B cells and constitutive expression in memory B cells. Blood. 2003;101(11):4500-4504.

51. Ruprecht CR, Lamzavecchia A. Toll-like receptor stimulation as a third signal required for activation of human naïve B cells. Eur J Immunol. 2006;36(4):810-816.

52. Eckl-Dorna J, Batista FD. BCR-mediated uptake of antigen linked to TLR9 ligand stimulates B-cell proliferation and antigen-specific plasma cell formation. Blood. 2009;113(17):3969-3977.

53. Krieg AM, Yi AK, Matson S, et al. CpG motifs in bacterial DNA trigger direct B-cell activation. Nature. 1995;374:546-548.

54. Davis HL, Weeranta R, Waldschmidt TJ, Tygrett L, Schorr J, Krieg AM. CpG DNA is a potent enhancer of specific immunity in mice immunized with recombinant hepatitis B surface antigen. J Immunol. 1998; 160(2):870-876.

55. Kobayashi H, Horner AA, Takabayashi K, et al. Immunostimulatory DNA pre-priming: a novel approach for prolonged Th1-biased immunity. Cell Immunol. 1999;198(1):69-75

56. Jung J, Yi AK, Zhang X, Choe J, Li L, Choi YS. Distinct response of human B cell subpopulations in recognition of an innate immune signal, CpG DNA. J Immunol. 2002;169(5):2368-2373.

57. Klinman DM, Yi AK, Beaucage SL, Conover J, Krieg AM. CpG motifs present in bacteria DNA rapidly induce lymphocytes to secrete interleukin 6, interleukin 12, and interferon gamma. Proc Natl Acad Sci U S A. 1996;93(7):2879-2883.

58. Akira S, Uematsu S, Takeuchi O. Pathogen recognition and innate immunity. Cell. 2006;124(4):783-801.

59. Bernasconi HL, Traggiai E, Lanzavecchia A. Maintenance of serological memory by polyclonal activation of human memory B cells. Science. 2002;298(5601):2199-2202.

60. Krieg AM. Therapeutic potential of Toll-like receptor 9 activation. Nat Rev Drug Discov. 2006;5(6):471-484.

61. Lambrecht BN, Hammad H. The airway epithelium in asthma. Nat Med. 2012;18(5):684-692.

62. Johnson J, Wiley RE, Fattouh R, et al. Continous exposure to house dust mite elicits chronic airway inflammation and structural remodeling. Am J Respir Crit Care. 2004;169(3):378-385.

63. Busse WW, lemanske RF Jr. Asthma. N Engl Med. 2001;344(5): 350-362.

64. Mazzarella G, Bianco A, Catena E, De Palma R, Abbate GF. Th1/ Th2 lymphocyte polarization in asthma. Allergy. 2000;55(Suppl 61): 6-9.

65. Wills-Karp M. Immunologic basis of antigen-induced airway hyperresponsiveness. Annu Rev Immunol. 1999;17:255-281.

66. Wohleben G, Erk KJ. Atopic disorders: a vaccine around the corner? Trends Immunol. 2001;22(11):618-626.

67. Cox L, Nelson H, Lockey R, et al. Allergen immunotherapy: a practice parameter third update. J Allergy Clin Immunol. 2011;127(Suppl 1): S1-S55.

68. Kline JN, Krieg AM. Toll-like receptor 9 activation with $\mathrm{CpG}$ oligodeoxynucleotides for asthma therapy. Drug News Perspect. 2008; 21(8):434-439.

69. Fonseca DE, Kline JN. Use of CpG oligonucleotides in treatment of asthma and allergic disease. Adv Drug Deliv Rev. 2009;61(3):256-262.

70. Pulsawat P, Pitakpolrat P, Prompetchara E, et al. Optimization of a Der p 2-biased prophylactic DNA vaccine against house dust mite allergy. Immunol Lett. 2013;151(1-2):23-30.

71. Heeg K, Zimmermann S. CpG DNA as a Th1 trigger. Int Arch Allergy Immunol. 2000;121(2):87-97.

72. Mo JH, Park SW, Rhee CS, et al. Suppression of allergic response by $\mathrm{CpG}$ motif oligodeoxynucleotide-house-dust mite conjugate in animal model of allergic rhinitis. Am J Rhinol. 2006;20(2): 212-218.

73. Li J, Pei H, Zhu B, et al. Self-assembled multivalent DNA nanostructures for noninvasive intracellular delivery of immunostimulatory $\mathrm{CpG}$ oligonucleotides. ACS Nano. 2011;5(11):8783-8789. 
74. Schmidt M, Anton K, Nordhaus C, Junghans C, Wittig B, Worm M. Cytokine and Ig-production by $\mathrm{CpG}$-containing sequences with phosphorodiester backbone and dumbbell-shape. Allergy. 2006;61(1): 56-63.

75. Schmidt M, Hagner N, Marco A, Konig-Merediz SA, SchroffM, Wittig B. Design and structural requirements of the potent and safe TLR-9 agonistic immunomodulator MGN1703. Nucleic Acid Ther. 2015; 25(3):130-140.

76. Weihrauch MR, Richly H, von Bergwelt-Baildon MS, et al. Phase I clinical study of the toll-like receptor 9 agonist MGN1703 in patients with metastatic solid tumors. Eur J Cancer. 2015;51(2):146-156.

77. Schmoll H-J, Wittig B, Arnold D, et al. Maintenance treatment with the immunomodulator MGN1703, a Toll-like receptor 9 (TLR9) agonist, in patients with metastatic colorectal carcinoma and disease control after chemotherapy: a randomised, double-blind, placebo-controlled trial. J Cancer Res Oncol. 2014;140(9):1615-1624.

78. Koo J-E, Shin S-W, Um S-H, Lee J-Y. X-shaped DNA potentiates therapeutic efficacy in colitis-associated colon cancer through dual activation of TLR9 and inflammasomes. Mol Cancer. 2015;14:104.

79. Mohri K, Nishikawa M, Takahashi N, et al. Design and development of nanosized DNA assemblies in polypod-like structures as efficient vehicles for immunostimulatory $\mathrm{CpG}$ motifs to immune cells. $A C S$ Nano. 2012;6(7):5931-5940.

80. Nishikawa M, Ogawa K, Umeki Y, et al. Injectable, self-gelling, biodegradable, and immunomodulatory DNA hydrogel for antigen delivery. J Control Release. 2014;180:25-32.

81. Ishii-Mizuno Y, Umeki Y, Takahashi Y, et al. Nasal delivery of Japanese cedar pollen Cryj1 by using self-gelling immunostimulatory DNA for effective induction of immune responses in mice. J Control Release. 2015;200:52-59.

82. Sakurai K, Mizu M, Shinkai S. Polysaccharide-polynucleotide complexes. 2. Complementary polynucleotide mimic behavior of the natural polysaccharide schizophyllan in the macromolecular complex with single-stranded RNA and DNA. Biomacromolecules. 2001;2(3): 641-650.

83. Kobiyama K, Aoshi T, Narita H, et al. Nonagonistic Dectin-1 ligand transforms $\mathrm{CpG}$ into a multitask nanoparticulate TLR9 agonist. Proc Natl Acad Soc U S A. 2014;111(8):3086-3091.

84. Heit A, Schmitz F, O’Keeffe M, et al. Protective CD8 T cell immunity triggered by $\mathrm{CpG}$-protein conjugates competes with the efficacy of live vaccines. J Immunol. 2005;174(7):4373-4380.

85. Cho HJ, Takabayashi K, Cheng P-M, et al. Immunostimulatory DNAbased vaccines induce cytotoxic lymphocyte activation by a T-helper cell-independent mechanism. Nat Biol. 2000;18(5):509-514.

86. Suzuki M, Ohta N, Min W-P, et al. Immunotherapy with CpG DNA conjugated with $\mathrm{T}$-cell epitope peptide of an allergenic Cry $\mathrm{j} 2$ protein is useful for control of allergic conditions in mice. Int Immunopharcol. 2007:7(1):46-54.

87. Karuraki Y, Fujimura T, Masuda K, et al. Induction of Th1 immune responses to Japanese cedar pollen allergen (Cry j 1) in mice immunized with Cryj 1 conjugated with $\mathrm{CpG}$ oligodeoxynucleotide. Comp Immunol Microbiol Infect Dis. 2011;34(2):157-161.

88. Salem AK. A promising CpG adjuvant-loaded nanoparticle-based vaccine for treatment of dust mite allergies. Immunotherapy. 2014; 6(11):1161-1163

89. Shirota H, Klinman DM. CpG-conjugated apoptotic tumor cells elicit potent tumor-specific immunity. Cancer Immunol Immunother. 2011; 60(5):659-669.

90. Gungor B, Yagci FC, Tincer G, et al. CpG ODN nanorings induce IFN $\alpha$ from plasmacytoid dendritic cells and demonstrate potent vaccine adjuvant activity. Sci Transl Med. 2014;6:235ra61.

91. Joshi VB, Adamcakova-Dodd A, Jing X, et al. Development of poly(lactic-co-glycolic acid) particle vaccine to protect against house dust mite induced allergy. AAPS J. 2014;16(5):975-985.

92. Joshi VB, Geary SM, Salem AK. Biodegradable particles as vaccine delivery systems: size matters. AAPS J. 2013;15(1):85-93.
93. Nikitczuk KP, Schloss RS, Yarmush ML, Lattime EC. PLGA-polymer encapsulating tumor antigen and CpG DNA administered into the tumor microenvironment elicits a systemic antigen-specific IFN- $\gamma$ response and enhances survival. J Caner Ther. 2013;4(1):280-290.

94. Lv S, Wang J, Dou S, et al. Nanoparticles encapsulating hepatitis B virus cytosine-phosphate-guanosine induce therapeutic immunity against HBV infection. Hepatology. 2014;59(2):385-394.

95. Speiser DE, Schwarz K, Baumgaertner P, et al. Memory and effector CD8 T-cell responses after nanoparticle vaccination of melanoma patients. J Immunother. 2010;33(8):848-858.

96. Senti G, Johansen P, Haug S, et al. Use of A-type CpG oligodeoxynucleotides as an adjuvant in allergen-specific immunotherapy in humans: a phase I/IIa clinical trial. Clin Exp Allergy. 2009;39(4): 562-570.

97. Beeh K-M, Kanniess F, Wagner F, et al. The novel TLR-9 agonist Q $\beta$ G10 shows clinical efficacy in persistent allergic asthma. J Allergy Clin Immunol. 2013;131(3):866-874.

98. Kundig TM, Klimek L, Schendzieloz P, Renner WA, Senti G, Bachmann MF. Is the allergen really needed in allergy immunotherapy? Curr Treat Options Allergy. 2015;2(1):72-82.

99. Casale TB, Cole J, Beck E, et al. CYT003, a TLR9 agonist, in persistent allergic asthma - a randomized placebo-controlled Phase 2B study. Allergy. 2015;70(9):1160-1169.

100. Kwon S, Kim D, Park B, et al. Induction of immunological memory response by vaccination with TM4SF5 epitope-CpG-DNA-liposome complex in a mouse hepatocellular carcinoma model. Oncology Rep. 2013;29(2):735-740.

101. Kwon S, Kim Y-E, Park J-A, Kim D-S, Kwon H-J, Lee Y. Therapeutic effect of a TM4SF5-specific peptide vaccine against colon cancer in a mouse model. BMB Rep. 2014;47(4):215-220.

102. Erikci E, Gursel M, Gursel I. Differential immune activation following encapsulation of immunostimulatory $\mathrm{CpG}$ oligodeoxynucleotide in nanoliposomes. Biomaterials. 2011;32(6):1715-1723.

103. Slutter B, Bal SM, Ding Z, Jiskoot W, Bouwstra JA. Adjuvant effect of cationic liposomes and $\mathrm{CpG}$ depends on administration route. $J$ Control Release. 2011;154(2):123-130.

104. Chen S, Zhang H, Shi X, Wu H, Hanagata N. Microfluidic generation of chitosan/CpG oligodeoxynucleotide nanoparticles with enhanced cellular uptake and immunostimulatory properties. Lab Chip. 2014; 14(11):1842-1849.

105. Manoharan Y, Ji Q, Yamazaki T, et al. Effect of molecular weight of polyethyleneimine on loading of $\mathrm{CpG}$ oligodeoxynucleotides onto flake-shell silica nanoparticles for enhanced TLR9-mediated induction of interferon- $\alpha$. Int J Nanomed. 2012;7:3625-3635.

106. Zhang H, Feng S, Yan T, Zhi C, Gao X-D, Hanagata N. Polyethyleneimine-functionalized boron nitride nanospheres as efficient carriers for enhancing the immunostimulatory effect of $\mathrm{CpG}$ oligodeoxynucleotides. Int J Nanomed. 2015;10:5343-5353.

107. Zhang H, Chen S, Zhi C, Yamazaki T, Hanagata N. Chitosan-coated boron nitride nanoparticles enhance delivery of $\mathrm{CpG}$ oligodeoxynucleotides and induction of cytokines. Int J Nanomed. 2013;8:1783-1793.

108. Xu Y, Claiden P, Zhu Y, Morita H, Hanagata N. Effect of amino groups of mesoporous silica nanoparticles on $\mathrm{CpG}$ oligodeoxynucleotide delivery. Sci Technol Adv Mater. 2015;16(4):045006.

109. Wei M, Chen N, Li J, et al. Polyvalent immunostimulatory nanoagents with self-assembled $\mathrm{CpG}$ oligonucleotide-conjugated gold nanoparticles. Angew Chem Int Ed. 2012;51(5):1202-1206.

110. Zhang H, Yamazaki T, Zhi C, Hanagata N. Identification of a boron nitride nanosphere-binding peptide for the intracellular delivery of CpG oligodeoxynucleotides. Nanoscale. 2012;4(20):6343-6450.

111. Ballester M, Jeanbart L, de Titta A, et al. Nanoparticle conjugation enhances the immunomodulatory effects of intranasally delivered $\mathrm{CpG}$ in house dust mite-allergic mice. Sci Rep. 2015;5:14274.

112. Jeanbalt L, Ballester M, de Titta A, et al. Enhancing efficacy of anticancer vaccines by targeted delivery to tumor-draining lymph nodes. Cancer Immunol Res. 2014;2(5):436-447. 
113. Zhao D, Alizadeh D, Zhang L, et al. Carbon nanotubes enhance CpG uptake and potentiate antiglioma immunity. Clin Cancer Res. 2011; 17(4):771-782.

114. Hirsh V, Paz-Ares L, Boyer M, et al. Randomized phase III trial of paclitaxel/carboplatin with or without PF-3512676 (Toll-like receptor 9 agonist) as first-line treatment for advanced non-small-cell lung cancer. J Clin Oncol. 2011;29(19):2667-2674.
115. Manegold C, van Zandwijk N, Szczesna A, et al. A phase III randomized study of gemcitabine and cisplatin with or without PF-3512676 (TLR9 agonist) as first-line treatment of advanced non-small-cell lung cancer. Ann Oncol. 2012;23(1):72-77.

International Journal of Nanomedicine

\section{Publish your work in this journal}

The International Journal of Nanomedicine is an international, peerreviewed journal focusing on the application of nanotechnology in diagnostics, therapeutics, and drug delivery systems throughout the biomedical field. This journal is indexed on PubMed Central, MedLine, CAS, SciSearch $®$, Current Contents $\circledR /$ Clinical Medicine,
Journal Citation Reports/Science Edition, EMBase, Scopus and the Elsevier Bibliographic databases. The manuscript management system is completely online and includes a very quick and fair peer-review system, which is all easy to use. Visit http://www.dovepress.com/ testimonials.php to read real quotes from published authors.

Submit your manuscript here: http://www.dovepress.com/international-journal-of-nanomedicine-journal 